\title{
Physiological and Biochemical Mechanisms and Cytology of Cold Tolerance in Brassica napus
}

OPEN ACCESS

Edited by:

Diana Santelia,

ETH Zürich, Switzerland

Reviewed by:

Leila Priscila Peters,

University of São Paulo, Brazil

Faisal Islam,

Zhejiang University, China

*Correspondence:

Wancang Sun

18293121851@163.com

Specialty section:

This article was submitted to

Plant Abiotic Stress,

a section of the journal

Frontiers in Plant Science

Received: 17 December 2019

Accepted: 28 July 2020

Published: 12 August 2020

Citation:

Qi W, Wang F, Ma L, Qi Z, LiU S, Chen C, Wu J, Wang $P$, Yang $C, W u Y$ and Sun W (2020) Physiological and

Biochemical Mechanisms and Cytology of Cold Tolerance in Brassica napus.

Front. Plant Sci. 11:1241.

doi: 10.3389/fpls.2020.01241

\begin{abstract}
Weiliang Qi $i^{1,2,3,4}$, Fei Wang ${ }^{4}$, Li Ma ${ }^{1,2,3}$, Ze Qi ${ }^{5}$, Songqing Liu ${ }^{4}$, Cun Chen ${ }^{4}$, Junyan $W u^{1,2,3}$, Ping Wang ${ }^{4}$, Cairong Yang ${ }^{4}$, Yong $W_{u^{4}}$ and Wancang Sun ${ }^{1,2,3 *}$

${ }^{1}$ College of Agronomy, Gansu Agricultural University, Lanzhou, China, ${ }^{2}$ Gansu Provincial Key Laboratory of Arid land Crop Science, Gansu Agricultural University, Lanzhou, China, ${ }^{3}$ Key Laboratory of Crop Genetics Improvement and Germplasm Enhancement of Gansu Province, Lanzhou, China, ${ }^{4}$ College of Chemistry and Life Science, Chengdu Normal University, Chengdu, China, ${ }^{5}$ College of Metallurgy, Northeastern University, Shenyang, China
\end{abstract}

Cold damage has negatively impacted the yield, growth and quality of the edible cooking oil in Northern China and Brassica napus L.(rapeseed) planting areas decreased because of cold damage. In the present study we analyzed two Brassica napus cultivars of 16NTS309 (highly resistant to cold damage) and Tianyou2238 (cold sensitive) from Gansu Province, China using physiological, biochemical and cytological methods to investigate the plant's response to cold stress. The results showed that cold stress caused seedling dehydration, and the contents of malondialdehyde (MDA), relative electrolyte leakage and $\mathrm{O}_{2}^{-}$and $\mathrm{H}_{2} \mathrm{O}_{2}$ were increased in Tianyou2238 than $16 \mathrm{NTS} 309$ under cold stress at $4^{\circ} \mathrm{C}$ for $48 \mathrm{~h}$, as well as the proline, soluble protein and soluble sugars markedly accumulated, and antioxidant enzymes of peroxidase (POD), superoxide dismutase (SOD), and catalase (CAT) were higher in 16NTS309 compared with in Tianyou2238, which play key roles in prevention of cell damage. After exposure to cold stress, the accumulation of the blue formazan precipitate and reddish brown precipitate indicated that $\mathrm{O}_{2}{ }^{-}$and $\mathrm{H}_{2} \mathrm{O}_{2}$, respectively, were produced in the root, stem, and leaf were higher than under noncold conditions. Contents of $\mathrm{O}_{2}^{-}$and $\mathrm{H}_{2} \mathrm{O}_{2}$ in cultivar Tianyou2238 were higher than 16NTS309, this is consistent with the phenotypic result. To understand the specific distribution of $\mathrm{O}_{2}^{-}$in the sub-cellular, we found that in both cultivars $\mathrm{O}_{2}{ }^{-}$signals were distributed mainly in cambium tissue, meristematic cells, mesophyll cytoplasm, and surrounding the cell walls of root, stem, leaves, and leaf vein by morphoanatomical analysis, but the quantities varied. Cold stress also triggered obvious ultrastructural alterations in leaf mesophyll of Tianyou2238 including the damage of membrane system, destruction of chloroplast and swelling of mitochondria. This study are useful to provide new insights about the physiological and biochemical mechanisms and cytology associated with the response of $B$. napus to cold stress for use in breeding cold-resistant varieties.

Keywords: Brassica napus, cold stress, super-oxide anion $\left(\mathrm{O}_{2}^{-}\right)$, physiological index, biochemical index, cytology 


\section{INTRODUCTION}

Rapeseed (Brassica napus L.) is an important oilseed crop in the world with sown area exceeding 7 million hectares in China. Rapeseed is divided into winter and spring types, most of which is winter type with more than $90 \%$ (Yan et al., 2019). Winter $B$. napus is mainly distributed in the Huang - Huai River and Yangteze River basin, but the same B. napus varieties were difficult to survive in northern China (Pu et al., 2019b). As a winter cover crop, B. napus not only eliminates the dust source of the damaging sand storms in northern China, but are also economically beneficial in the dry and cold regions of northwest China. In China, cold affected area of winter rape of the B. napus accounts for $77.8 \%$ and planting areas has been reduced by about $10.9 \%$ because of cold damage, such as an extremely cold weather, ice rain and heavy snow. Cold damage has negatively impacted the yield, growth, and quality of the edible cooking oil in China (Sun et al., 2007; Zhang et al., 2008; Sun et al., 2010; Huang et al., 2019). Many studies also shown that B. rapa has better cold resistance than B. napus (Sun et al., 2007; Sun, 2013), and several B. rapa species have been successfully cultivated in northern China. Thus, it is urgent to develop more cold resistant varieties of $B$. napus. In order to survive in harsh natural environment conditions, plants have evolved complex mechanisms, such as accumulation of compatible osmolytes, stimulation of efficient enzymatic and non-enzymatic antioxidative system (Dietz et al., 2006; Meyer et al., 2012; Noctor et al., 2014). Cold stress lead to the accumulation of excess reactive oxygen species (ROS) such as super-oxide anion $\left(\mathrm{O}_{2}^{-}\right)$, hydrogen peroxide $\left(\mathrm{H}_{2} \mathrm{O}_{2}\right)$, oxygen singlet oxygen $\left({ }^{1} \mathrm{O}_{2}\right)$ and the hydroxyl radical (HO.)(Asada and Takahashl, 1987; Mittler et al., 2004; Tripathi et al., 2017; Banerjee et al., 2018; Huang et al., 2019) which cause oxidative stress and lead to a variety of biochemical and structural changes and cell death (Apel and Hirt, 2004; Vacca et al., 2004; Vacca et al., 2006; Lushchak, 2014; Marcec et al., 2019). ROS signaling has been studied in plant cells, but still unclear. Gill and Tuteja (2010) reported that chloroplasts of photosystem I and II (PSI and PSII), and mitochondria of complex I, ubiquinone and complex III of electron transport chain (ETC) are the major sites for the generation of $\mathrm{O}_{2}{ }^{-}$(Zhao et al., 2018). But also are 'deliberately' produced at plasma membrane level, or extracellularly in plants such as class cell wall-peroxidases, germin-like oxalate oxidase,s and amine oxidases and plant NADPH oxidases, which are by far the most studied $\mathrm{O}_{2}{ }^{-}$producing enzymes (Apel and Hirt, 2004; Miller et al., 2010; Nanda et al., 2010; Gilroy et al., 2016; Singh et al., 2017). As diffusible and short-lived molecules, $\mathrm{O}_{2}{ }^{-}$were unable to transport across the membrane's lipid bilayer, but $\mathrm{O}_{2}{ }^{-}$ could be converted into hydrogen peroxide $\left(\mathrm{H}_{2} \mathrm{O}_{2}\right)$ by variety of reactions (Gilroy et al., 2016; Toyota et al., 2018; Singh et al., 2019) that readily transferred across membranes passively. We can therefore envision ROS $\left(\mathrm{O}_{2}{ }^{-}, \mathrm{H}_{2} \mathrm{O}_{2}\right.$, etc. $)$ signaling as a dynamic process that occurs within cells between different organelles, as well as between cells over long distances (Mittler et al., 2011). More importantly, ROS $\left(\mathrm{O}_{2}{ }^{-}, \mathrm{H}_{2} \mathrm{O}_{2}\right.$, etc. $)$ can regulate a broad range of biological processes (Mittler et al., 2004; Mittler et al.,
2011). Suzuki et al. (2011) reported that 345 or 97 transcripts are up-regulated specifically by $\mathrm{H}_{2} \mathrm{O}_{2}$ or $\mathrm{O}_{2}{ }^{-}$, respectively, indicating that distinct signaling pathways were activated by these different $\operatorname{ROS}\left(\mathrm{O}_{2}{ }^{-}, \mathrm{H}_{2} \mathrm{O}_{2}\right.$, etc.). Thus, localizing the $\mathrm{O}_{2}{ }^{-}$signal at the subcellular is essential for us to gain deep knowledge of the mechanisms of $\mathrm{O}_{2}{ }^{-}$production, transduction of $\mathrm{O}_{2}^{-}$derived signals, and especially the communication and interaction between different subcellular compartments in $\mathrm{O}_{2}{ }^{-}$signaling.

Our research group studied the feasibility of expanding winter rapeseed northwards into cold regions in northwestern China and bred new $B$. napus 16 NTS309 having a strong cold tolerance, which could over winter in the $36^{\circ} 73^{\prime} \mathrm{N}$ area at an altitude of $1,517 \mathrm{~m}$. These are the essential B. napus germplasm resources having strong cold tolerance levels used for breeding in northern China. Although the physiology, proteomics, and micRNA of cold tolerance of winter B. napus and B.rape have been studied (Ma et al., 2019; Pu et al., 2019b), but the cellular mechanisms underlying cold tolerance and resistance (Møller and Sweetlove, 2010) remain largely unknown. In this study, we address several key questions. Where do $\mathrm{O}_{2}{ }^{-}$come from and are there differences in the accumulation of $\mathrm{O}_{2}{ }^{-}$in $B$. napus of root, stem, leaves, and leaf vein? Do $\mathrm{O}_{2}{ }^{-}$diffuse in the cytoplasm of cells and, if so, to what degree? What Kinds of modifications in plant growth, ultrastructural modifications, and anti oxidative response to cold stress in B. napus? The aim is to provide new insights about the physiological and biochemical and cytology mechanisms associated with the response of $B$. napus to cold stress for use in breeding cold-resistant varieties.

\section{MATERIALS AND METHODS}

\section{Plant Material}

The B. napus cultivar 16NTS309 (strongly resistant to cold damage) and Tianyou 2238 (cold sensitive) provided by the Key Laboratory of Crop Genetics Improvement and Germplasm Enhancement of Gansu Province, Lanzhou. B. napus of 16NTS309 and Tianyou2238 were grown on experimental farm of Gansu Agricultural University of Lanzhou $\left(36^{\circ} 73^{\prime} \mathrm{N}\right.$, altitude $1,517 \mathrm{~m}$ ). The experiment was set up as a split-plot design with 3 replicates. The area of single plot was $4 \mathrm{~m}^{2}$, furrowing seeding (spacing planting distance $8-10 \mathrm{~cm}$ ). Sowing seeds in middle of September. The number of seedlings before overwintering stage and after overwintering datas was counted. The overwintering rates $(\%)=$ number of seedlings after overwintering stage/total number of seedling plants by $100 \%$.

In the laboratory, seeds were also germinated in $12 \times 8$ hole float tray $(60 \times 40 \times 8 \mathrm{~cm})$ and pots were filled with a 3:1 mixture of nutritional soil and vermiculite, and are grown in an illumination incubator with normal conditions $\left(25^{\circ} \mathrm{C}\right.$, day/night temperature, $16 \mathrm{~h}$ photoperiod, intensity of illumination $6000 \mathrm{Lx})$. Until the plants grew to the four-leaf stage, then 16NTS309 and Tianyou2238 seedlings were divided into two groups. One group was transferred to normal conditions $\left(25^{\circ} \mathrm{C}\right.$, day/night temperature, $16 \mathrm{~h}$ photoperiod, intensity of illumination 
$6000 \mathrm{Lx}$ ) and kept for $48 \mathrm{~h}$ as a non-cold control. The other group was placed into a pre-cooling incubator for cold treatment at $4^{\circ} \mathrm{C}$ for $48 \mathrm{~h}\left(4^{\circ} \mathrm{C}\right.$, day/night temperature, $16 \mathrm{~h}$ photoperiod, intensity of illumination $6000 \mathrm{Lx}$ ). The experiment was repeated three times.

\section{Plant Callus System}

A plant callus system of B. napus cultivar Tianyou2238 (cold sensitive) was established using the leaves. To characterize callus growth, seeds were surface sterilized with $0.5 \%$ hypochlorous acid $(\mathrm{HClO})$ for $8 \mathrm{~min}$ and germinated in the dark for $48 \mathrm{~h}$, then grown in $200 \mathrm{ml}$ flasks containing $50 \mathrm{ml}$ of liquid murashige and skoog (MS) medium. The resultant embryos were placed on callus-generating medium containing MS salts supplemented with $1 \mathrm{mg} . \mathrm{L}^{-1} 2$, 4-dichlorophenoxyacetic acid (2,4 - D) and $1 \mathrm{mg} \cdot \mathrm{L}^{-1}$ 6-benzylaminopurine (6 - BA) and adjusted to $\mathrm{pH} 6.0$, prior to autoclaving. The embryo cultures were maintained at $25^{\circ} \mathrm{C}$ in low light conditions. Then 100 calluses were obtained after 8 days of incubation. The calluses of cultivar Tianyou 2238 were divided into two groups: one was maintained at $25^{\circ} \mathrm{C}$ as the non-cold control and the other was subjected to cold stress at $4^{\circ} \mathrm{C}$ (Li et al., 1998).

\section{Physiological Index Method}

After the cold treatment, we used fresh materials immediately measured the relative electrolyte leakage by a digital conductometer DDS11A (Leici Instrument Factory, Shanghai, China) according to Bajji et al. (2002). $\mathrm{O}_{2}{ }^{-}$was measured as described by Elstner and Heupel (1976). $\mathrm{H}_{2} \mathrm{O}_{2}$ was measured as described by Sergiev et al. (1997). The content of soluble sugar, soluble protein, malondialdehyde (MDA), proline (Pro), superoxide dismutase (SOD), peroxidase (POD), and catalysis (CAT) measured using the frozen sample. Soluble sugar content was measured as described by Buysse and Merckx (1993). Soluble protein content was measured using coomassie brilliant blue staining (Zou, 2000). MDA was determined by the thiobarbituric acid (TBA) reaction (Dhindsa et al., 1981) and the content of Pro was measured by the sulfosalicylic acid-acid ninhydrin method (Bates et al., 1973). The activity assay of SOD, POD, and CAT were recorded according to $\mathrm{Wu}$ et al. (2003). All physiological results were repeated for three times and the data were analyzed by one-way analysis of variance (ANOVA) using SPSS 20.0 (IBM Corp., Armonk, NY, USA) to detect significant differences between both treatments $(\mathrm{P}<$ 0.05). Results were plotted with Adobe Photoshop CC 2018 (Adobe Inc., San Jose, CA, USA).

\section{Detection of $\mathrm{H}_{2} \mathrm{O}_{2}$ and $\mathrm{O}_{2}{ }^{-}$}

Seedlings were placed in the test tubes and immersed in 3, 3'Diaminobenzidine (DAB) and Nitrotetrazolium blue chloride (NBT) staining solution to detect $\mathrm{H}_{2} \mathrm{O}_{2}$ and $\mathrm{O}_{2}{ }^{-}$as described by Kumar et al. (2014) and Wu et al. (2015). Plants were immersed for $8 \mathrm{~h}$ with $\mathrm{DAB}$ and NBT staining solution that solution should be placed away from light. After infiltration, the stained plants were bleached in an acetic acid:glycerol: ethanol (1:1:3, v/v/v) solution at $100^{\circ} \mathrm{C}$ for $10-20 \mathrm{~min}$, then stored in $95 \%(\mathrm{v} / \mathrm{v})$ ethanol until scanned. The experiment was repeated six times.

\section{Transmission Electron Microscopy}

For ultrastructural analysis of leaf tissue, samples were fixed with $2.5 \%$ gluteraldehyde fixative in $0.1 \mathrm{M}$ phosphate buffered saline (PBS) at $\mathrm{pH} 7.4$ for $2 \mathrm{~h}$ under vacuum. Then, the samples were rinsed repeatedly with $\mathrm{PBS}$ before and after secondary fixing with $2 \%$ osmium tetroxide. The fixed samples were polymerized in epoxy resin, in an oven at $70^{\circ} \mathrm{C}$ for a day. The resulting polymerised resin blocks were sectioned at 60-100 nm thickness with an ultramicrotome and mounted on copper grids for observation with a transmission electron microscope (STEM CM12, Philips). Digital micrographs were captured and stored (Stefanowska et al., 2002; Ali et al., 2018a).

\section{Tissue Section}

NBT reacts specifically with superoxide and forms a blue formazan precipitate. The deepest root, stem, and leaf samples from cultivars 16NTS309 and Tianyou2238 that had blue formazan precipitate areas, were sectioned and used for the morphoanatomical analysis. The samples were fixed in formalin acetoalcohol (FAA) 50\%, softened using $20 \%$ ethylenediamine, and embedded in paraffin. The samples were sectioned on a rotary microtome and stained with PAS-naphthol yellow or saffron-solid green. Slides were mounted with synthetic resin and images were captured using a digital image acquisition system.

\section{Chromosome Preparation}

Seedlings of cultivars 16NTS309 and Tianyou2238 from winter oilseed rape (B. napus) were germinated on moist filter paper until the primary roots were $2-3 \mathrm{~cm}$ long. Then root tips were removed in $2 \%(\mathrm{w} / \mathrm{v})$ cellulase (Calbiochem) and 20\% (v/v) pectinase (Sigma Aldrich Corp., St Louis, MO, USA) in enzyme mixture for $40 \mathrm{~min}$ at $37^{\circ} \mathrm{C}$. Chromosomes were prepared using a method adapted from Snowdon et al. (2002).The chromosomes were finally counter stained with DAPI (4, 6 - diamidino - 2 - phenylindole) solution (Vector Laboratories, Inc., Burlingame, CA, USA). The images were captured with an Olympus BX-51 (Olympus Corp., Tokyo, Japan) fluorescence microscope coupled to a Photometric SenSys Olympus DP70 CCD camera (Qi et al., 2016).

\section{RESULTS}

\section{Karyotype Analysis}

B. napus $(2 \mathrm{n}=38$; $\mathrm{AA}+\mathrm{CC})$ originated from the spontaneous hybridization of $B$. rapa $(2 \mathrm{n}=20 ; \mathrm{AA})$ and Brassica oleracea $\mathrm{L}$. $(2 \mathrm{n}=18$; CC) and contains the entire diploid chromosome sets of both parental genomes. The chromosomes of the highly homoeologous A genome of B. rapa and $\mathrm{C}$ genome of $B$. oleracea diverged relatively recently from a common ancestor (Lagercrantz and Lydiate, 1996). The 16NTS309 and Tianyou2238 cultivars, which belong to the tetraploid $B$. napus line $(2 \mathrm{n}=4 \mathrm{X}=38$; AACC) as determined by chromosome karyotype analysis 



FIGURE 1 | The chromosomes were counter stained with the DAPI solution. B. napus cultivars of (A) 16 NTS309 and (B) Tianyou2238.

(Figures 1A, B), were originally produced in our laboratory (Research Institute, Gansu Agricultural University, Gansu, China).

\section{Morphological and Physiological Responses to Cold Stress}

Two B. napus varieties were used as the materials. In order to compare the difference of cold tolerance between these materials in the natural environment, we observed the morphology of seedlings before overwintering (Figures 2A, B) in test fields of Lanzhou $\left(36^{\circ} 73^{\prime} \mathrm{N}\right.$, altitude $\left.1,517 \mathrm{~m}\right)$ and recorded statistical overwintering rate. The strong winter B. napus of 16 NTS309 could survive over winter in Lanzhou with average overwintering rates of $85.38 \%$, which was higher than Tianyou 2238 (Figure 3K).

Under normal conditions, two B. napus varieties were grown well (Figure 2C, D). After $48 \mathrm{~h}$ of cold stress at $4^{\circ} \mathrm{C}, 16 \mathrm{NTS} 309$ injury was minimal (Figure 2E), while the leaves of Tianyou2238 were showing marked wilting and chlorosis due to injury (Figure 2F). Under cold stress, the relative electrolyte leakage, $\mathrm{MDA}, \mathrm{O}_{2}{ }^{-}$, $\mathrm{H}_{2} \mathrm{O}_{2}$, soluble protein, proline, and soluble sugars content of both cultivars increased compared with their content under noncold conditions. However, relative electrolyte leakage (Figure 3H), MDA (Figure 3G), $\mathrm{O}_{2}^{-}$(Figure 3I), $\mathrm{H}_{2} \mathrm{O}_{2}$ (Figure 3J) increased by $187.33 \%, 84.81 \%, 170.49 \%$ and $53.84 \%$, respectively,

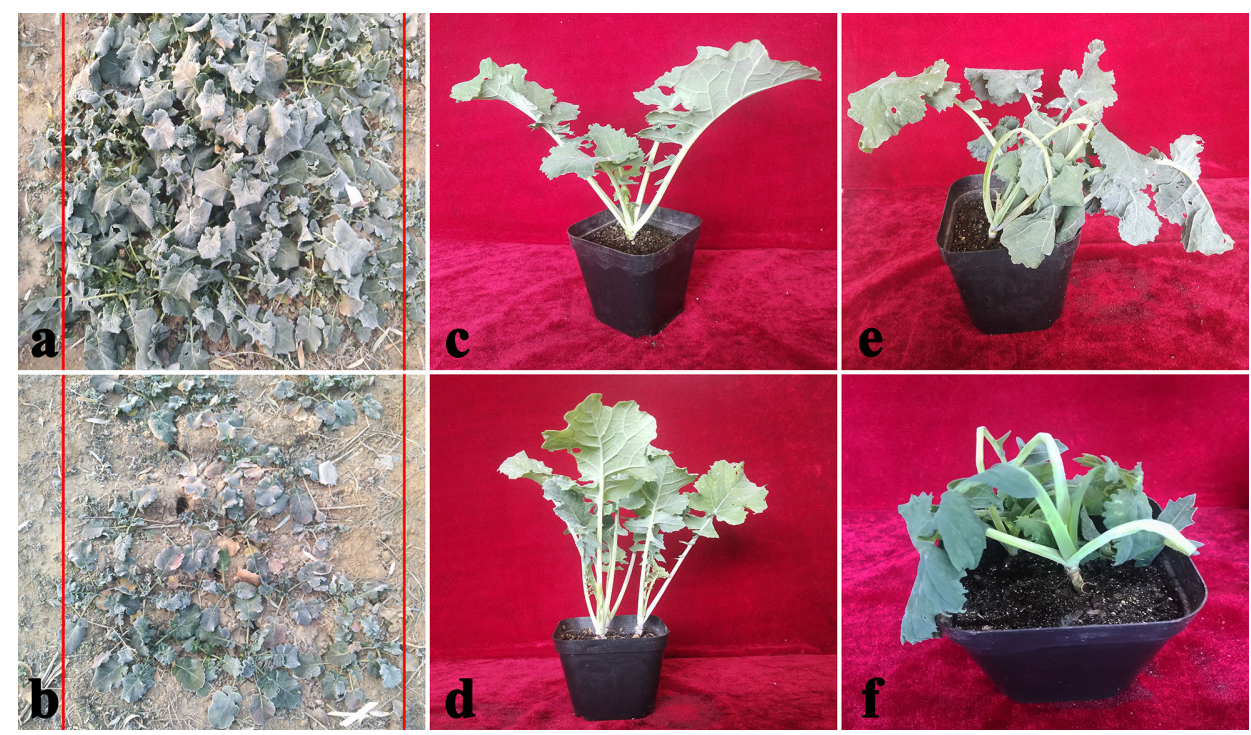

FIGURE 2 | Phenotypic symptoms of cultivars 16 NTS309 (A, C, E) and Tianyou2238 (B, D, F) in response to cold stress. Morphological characteristics of B. napus in December in the natural environment (A, B), representative phenotypes of the plants under non-cold (C, D), and cold stress conditions (E, F). 

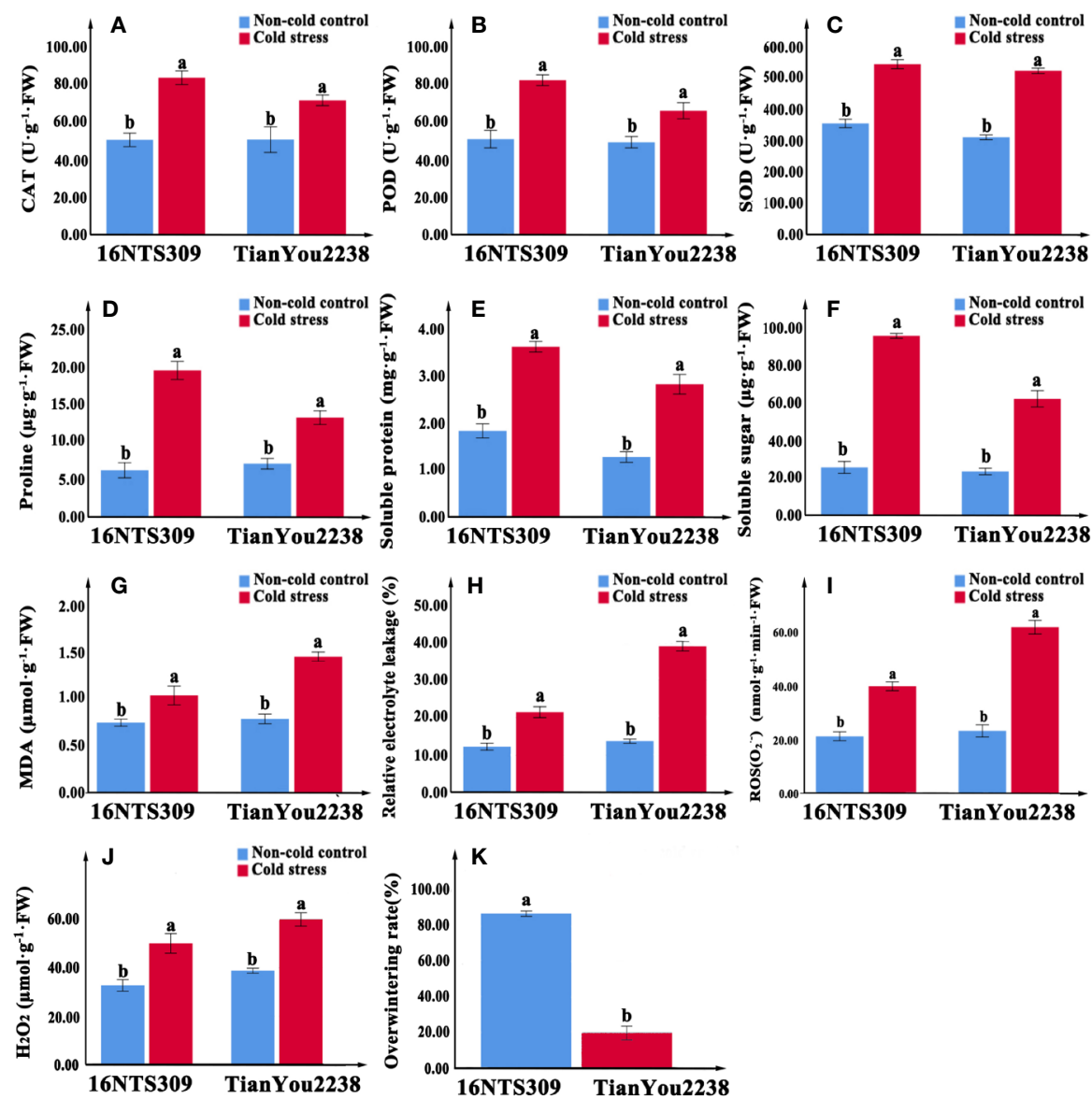

FIGURE 3 | The activity of catalase (CAT) (A), peroxidase (POD) (B), superoxide dismutase (SOD) (C), proline (D), protein (E), soluble sugars (F), malondialdehyde $(\mathrm{MDA})(\mathbf{G})$, relative electrolyte leakage $\mathbf{( H )}, \mathrm{O}_{2}{ }^{-} \mathbf{( I )}$, and $\mathrm{H}_{2} \mathrm{O}_{2} \mathbf{( J )}$ content accumulation in leaves of $16 \mathrm{NTS} 309$ and Tianyou2238 under cold stress at $4{ }^{\circ} \mathrm{C}$ for $48 \mathrm{~h}$. Overwintering rates was recorded in natural environment. Average overwintering rstes (K) in plants of 16NTS309 and Tianyou2238 under harsh winter conditions. The majuscules indicate a significant difference $(\mathrm{P}<0.05)$ for the data of the cold stress treated samples compared with non-cold stressed samples. The different small letters indicate significant differences at $p<0.05$. The mean values were calculated from three biological replicates. Error bars denote standard error of the mean.

in Tianyou2238 which were higher than in 16NTS309. The soluble protein, proline, and soluble sugars in 16NTS309 were increased by $94.62 \%, 219.14 \%$, and $271.3 \%$, respectively, which is higher than they were in Tianyou2238. The activity of SOD, POD, and CAT also was higher in 16NTS309 compared with in Tianyou2238. These indexes were increased by $52.99 \%$ (Figure 3C), 60.39\% (Figure 3B), and 65.92\% (Figure 3A), respectively.

\section{Morphological and Anatomical Evaluation of $\mathrm{O}_{2}^{-}$and $\mathrm{H}_{2} \mathrm{O}_{2}$}

NBT specifically reacts with $\mathrm{O}_{2}{ }^{-}$and forms a blue formazan precipitate. $\mathrm{DAB}$ is oxidized by $\mathrm{H}_{2} \mathrm{O}_{2}$ in the presence of peroxidases and produces reddish brown precipitate. The accumulation of the blue formazan precipitate and reddish brown precipitate indicated the production of the $\mathrm{O}_{2}{ }^{-}$and $\mathrm{H}_{2} \mathrm{O}_{2}$ in the root, stem, and leaf. Under normal conditions, seedlings of cold-tolerant cultivar 16NTS309 (Figures 4A, E) and cold sensitive cultivar Tianyou2238 (Figures 4C, G) also produce $\mathrm{O}_{2}^{-}$and $\mathrm{H}_{2} \mathrm{O}_{2}$ concentrations were in root, stem, and leaf. After exposure to cold stress, Tianyou2238 (Figures 4D, H) accumulated more $\mathrm{O}_{2}{ }^{-}$and $\mathrm{H}_{2} \mathrm{O}_{2}$ than $16 \mathrm{NTS} 309$ (Figures 4B, F).

The NBT stained blue sections of root, stem, leaf vein, and leaf samples from 16NTS309 and Tianyou2238 used for the morphoanatomical analysis were selected for histological observation. The results showed that in the roots, the epidermis, secondary phloem, secondary xylem, cambium, and vascular cylinder had wide parenchymatous rays (Figure 5). The primary structures of the stems, the epidermis and cortex, developed notable vascular cylinders (Figure 6). In the leaves, the upper epidermis, lower epidermis, vein, stomatal palisade tissue, and spongy tissue showed starch accumulation (Figure 7). The veins contain epidermis and vascular bundles (Figure 8). Significant differences in $\mathrm{O}_{2}{ }^{-}$production were found between the two cultivars and between the treatments. However the cambium, which is located between the phloem and xylem in roots, accumulated a lot of blue polymerization product after cold stress in both cultivars. Leaves mesophilic cells near the 


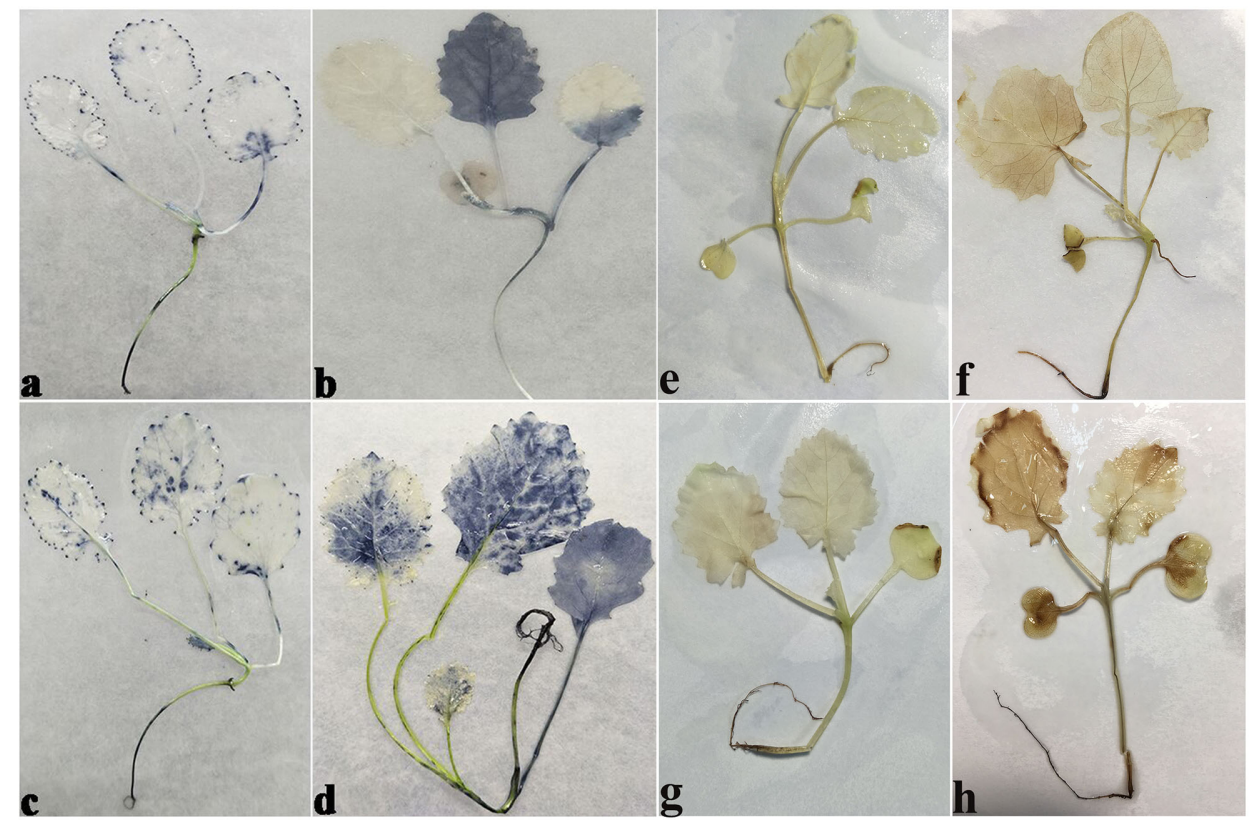

FIGURE 4 | The $\mathrm{O}_{2}^{-}$(A-D), $\mathrm{H}_{2} \mathrm{O}_{2}$ (E-H) levels in seedlings stained with Nitrotetrazolium blue chloride (NBT) and 3, 3'-Diaminobenzidine (DAB) of cultivars 16NTS309 and Tianyou2238 under non-cold (A, C, E, G) and cold stress (B, D, F, H) conditions. B. napus cultivars 16 NTS309 (A, B, E, F) and Tianyou2238 (C, D, G, H).

upper epidermis are cylindrical, forming the palisade tissue and mesophyll cells near the lower epidermis are irregular in shape and loose in arrangement, which were contains more chloroplasts. A greater $\mathrm{O}_{2}{ }^{-}$content accumulated in palisade tissue and mesophyll cells compared with that in other leaf cells. This result indicated that chloroplasts play an active role in the production of $\mathrm{O}_{2}^{-}$(Figures $7 \mathbf{B}, \mathbf{D}$ ). In other mesophyll tissue cells, $\mathrm{O}_{2}{ }^{-}$signals also were detected in mesophyll cytoplasm and surrounding cell walls, but the quantity in the two cultivars varied.

\section{Ultrastructural Analysis}

In order to study the damage to the leaf mesophyll cells caused by cold stress, we investigated the leaves of 16NTS309 and Tianyou 2238 with a transmission electron microscope. Under non-cold conditions, the leaf mesophyll cells had obvious organelles that showed no significant differences between the two cultivars and the shape of each cell was regular (Figures 9A-D and 10A-E). The outer envelope was clear and the chromatin inside was evenly distributed. The chloroplast shapes were lens-like and oblong, with the typical arrangement of grana and stroma thylakoids. After cold stress, more obvious alterations were observed in Tianyou2238 (Figures $\mathbf{1 0 F}-\mathbf{I}$ ) as compared to 16NTS309 (Figures 9E-H), the membrane system was not clear or complete and showed disintegration, chloroplasts were destroyed, mitochondria were swollen.

\section{$\mathrm{O}_{2}^{-}$Verification}

The in vitro culture of plant cells and tissues allows the cytology and physiology of plants to be study (Wani et al., 2010). We established a sterile rapid propagation system for leaf segments of Tianyou2238 and used it to deeply understand the rules of $\mathrm{O}_{2}{ }^{-}$ production and to verify the correctness of a previous analysis (Figure 11). After cold stress, we found that the meristematic tissue of roots, in which the cells have mitochondria but no chloroplasts, gathered more dark blue formazan precipitate than the meristematic tissue of roots under the non-cold conditions. This result indicated that mitochondria play an active role in the production of $\mathrm{O}_{2}{ }^{-}$(Figures 12D-F). In other mesophyll tissue cells, $\mathrm{O}_{2}{ }^{-}$signals were detected mainly in the meristematic zone and cell wall (Figures 12A-C), which is consistent with previous results.

\section{DISCUSSION}

\section{Winter Surviving Rate and Morphology Characteristics of $B$. napus}

Winter rapeseed (B. napus) is an important oil seed crop. As a cover crop, it helps to eliminate a dust source for the damaging sand storms in northern China. Growing winter rapeseed in dry and cold regions in northwestern China benefits economically, environmentally and ecologically (Sun et al., 2007; Sun, 2013). However, the low temperatures in the area of $35^{\circ} \mathrm{N}$ makes it difficult for B. napus varieties to survive (Sun et al., 2007; Huang et al., 2018). Our research group studied the feasibility of expanding winter rapeseed into cold regions in northwestern China and bred new lines of $B$. napus having a strong cold tolerance, which could over winter in the $36^{\circ} 73^{\prime} \mathrm{N}$ area at an altitude of $1,517 \mathrm{~m}$ (Pu et al., 2019b). In this study, winter surviving rate of B. napus variety (16NTS309) in the northwestern Lanzhou 


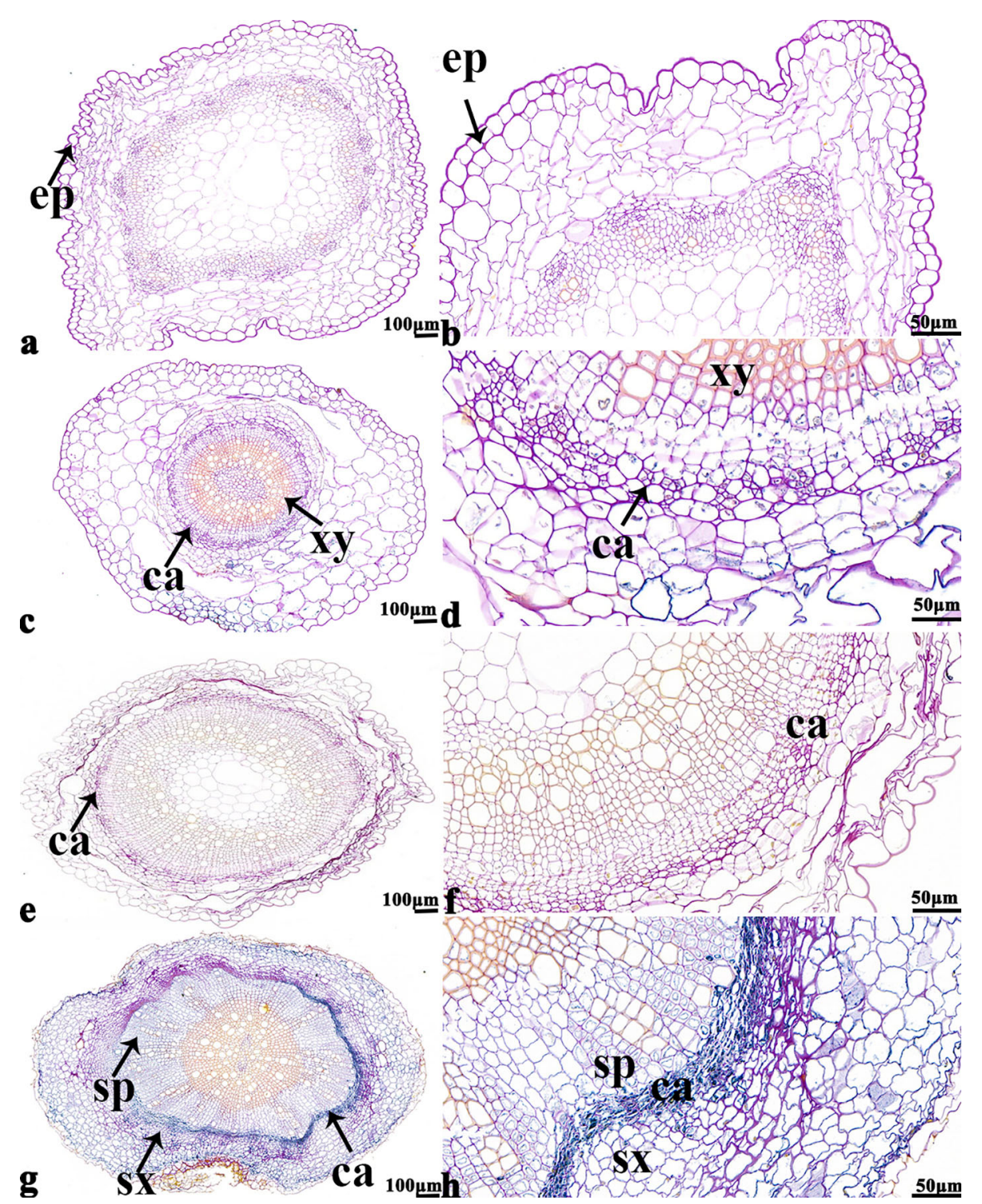

FIGURE 5 | B. napus cultivars 16 NTS309 and Tianyou2238 under non-cold (A, B, E, F) and cold stress (C, D, G, H) conditions for 48 h. The deepest root samples with blue formazan precipitate areas in 16NTS309 (A-D) and Tianyou2238 (E-H) were sectioned for morphoanatomical analysis. ep, epidermis; ca, cambium; sp, secondary phloem; sx, secondary xylem. Scale bars $=50 \mu \mathrm{m}$ and $100 \mu \mathrm{m}$.

$\left(36^{\circ} 73^{\prime} \mathrm{N}\right.$, altitude $\left.1517 \mathrm{~m}\right)$ reached $85.38 \%$, which was higher than Tianyou2238. This results indicated that 16NTS309 was a strong cold resistance, but Tianyou2238 was weaken for cold resistance. In order to adapt to low temperature, the morphology characteristics of B. napus are semi-erect or prostrate growth, leaves dark green or purplish red (Sun et al., 2007; Liu et al., 2013; Wang et al., 2015). The seedlings of B. napus of 16NTS309 tended to prostrate grow and the colors of leaves and young stems were yellow-green or purple in cold stress, which was consistent with morphological characteristics of cold tolerant B. napus (Sun et al., 2007; Liu et al., 2013; Wang et al., 2015; Pu et al., 2019b). Those results showed that 16NTS309 is good germplasm resources which can be used for strong cold tolerant B. napus breeding in northern China. To improve the cold tolerance, it is necessary to investigate the cold tolerance mechanism of winter $B$. napus.

\section{Physiochemical Changes of Winter $B$. napus After Cold Stress}

Cold stress causes dysfunctions at the cellular level (Bowers, 1994; Shao et al., 2008). Cold tolerance in plants is correlated with multiple mechanisms, such as changes in gene expression (Örvar et al., 2000), antioxidants (Kang and Saltveit, 2001; Shao et al., 2008), accumulation of osmotic adjustment substance, which are thought to play roles in prevention of cell damage (Ristic and Ashworth, 1993). Soluble sugars (Ma et al., 2009) and 


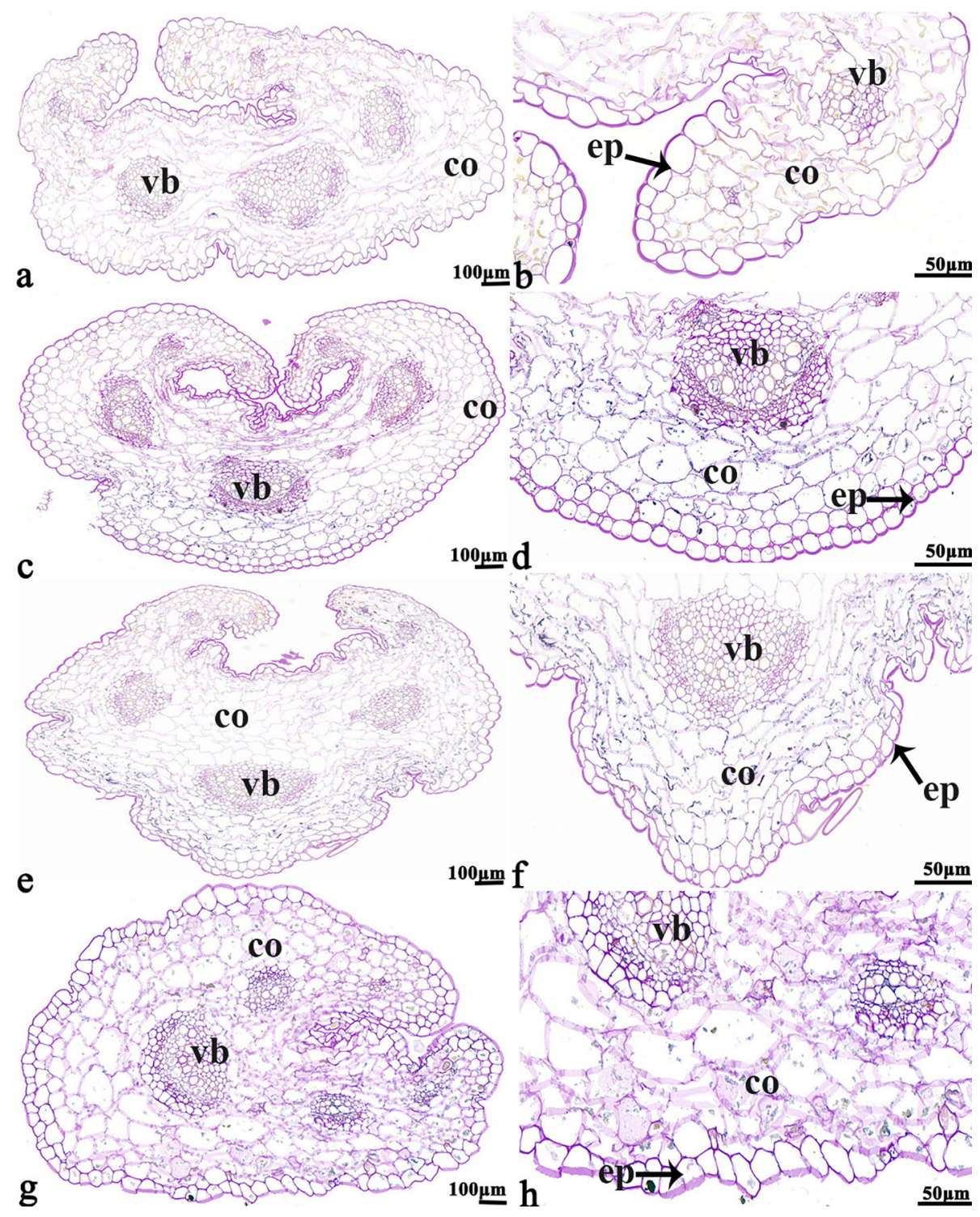

FIGURE 6 | B. napus cultivars 16 NTS309 and Tianyou2238 under non-cold (A, B, E, F) and cold stress (C, D, G, H) conditions for $48 \mathrm{~h}$. The deepest stem samples with blue formazan precipitate areas in 16NTS309 (A-D) and Tianyou2238 (E-H) were sectioned for morphoanatomical analysis. vb, vascular bundle; co, cortex; ep, epidermis. Scale bars $=50 \mu \mathrm{m}$ and $100 \mu \mathrm{m}$.

proline (Lalk and Dörffling, 1985; Wanner and Junttila, 1999; Kishor et al., 2005; Shao et al., 2008) occur in the cytosol where they contribute substantially to protect plant cells from damage caused by cold stress (Gajewska and Skłodowska, 2007). In this study, we found that proline (Figure 3D), protein (Figure 3E), and soluble sugars (Figure 3F) markedly accumulated in response to cold stress in the B. napus cultivars 16NTS309 and Tianyou2238. Antioxidant systems also protect plants from ROS that are generated as a result of cold stress. SOD is an antioxidant enzyme that plays a major role in the plant defence system against oxidative stress, and it is ubiquitous in every cell of all plant types (Ali et al., 2018b). SOD catalyses the conversion of toxic $\mathrm{O}_{2}{ }^{-}$radicals to $\mathrm{H}_{2} \mathrm{O}_{2}$ and oxygen $\left(\mathrm{O}_{2}\right)$ (Gokul et al., 2016), and $\mathrm{H}_{2} \mathrm{O}_{2}$ is subsequently detoxified to water $\left(\mathrm{H}_{2} \mathrm{O}\right)$ by $\mathrm{POD}$ and CAT. We found that the cold-resistant cultivar 16NTS309 had higher SOD (Figure 3C), POD (Figure 3B), and CAT (Figure 3A) activity than the cold-sensitive cultivar Tianyou2238. But, when the defense system was out of adjust, excessive accumulation of ROS from multiple sources resulted in ROS bursts which caused oxidative damage to nucleic acids, lipids and proteins etc. (John et al., 2010; Barna et al., 2012; Nath et al., 2016), and damaged other surrounding cells by cold stress (Yao et al., 2001; Chen and Dickman, 2004; Min et al., 2012; Zhu et al., 2019). Studies have also shown that the permeability of cell membranes and electrolyte leakage increase resulted in an increase in the relative conductivity of tissues under low temperature (Huang et al., 2018). MDA and 


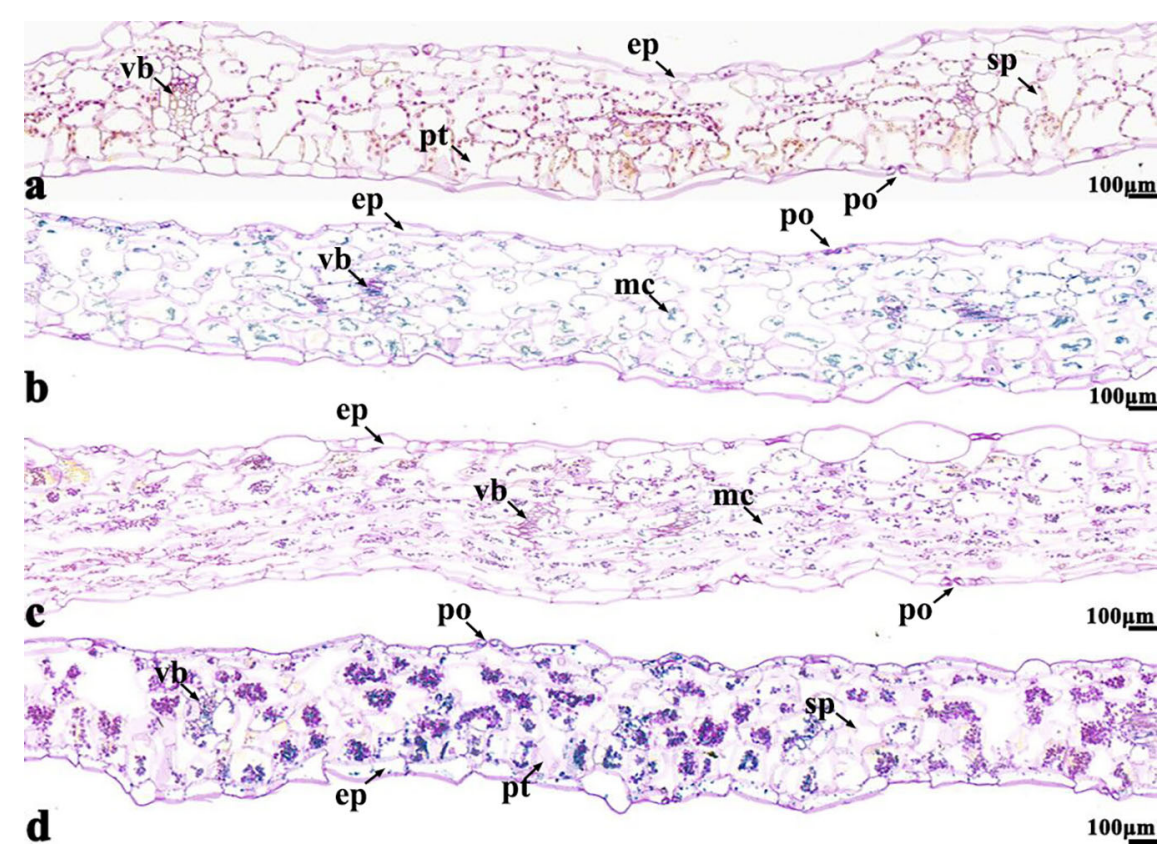

FIGURE 7 | B. napus cultivars 16NTS309 and Tianyou2238 under non-cold (A, C) and cold stress (B, D) conditions for 48 h. The deepest leaf samples with blue formazan precipitate areas in 16NTS309 (A, B) and Tianyou2238 (C, D) were sectioned for morphoanatomical analysis. po, pore; ep, epidermis; sp, spongy parenchyma; pt, palisade tissue; vb, vascular bundle; ep, epidermis. Scale bars $=100 \mu \mathrm{m}$.

relative electrolyte leakage can reflect the degree of membrane damage in cold stress (Lyons, 1973; Campos et al., 2003). We found that the MDA content of 16NTS309 and Tianyou2238 under cold stress for 48 h substantially increased by $40.54 \%$ and $84.81 \%$ (Figure 3G), respectively. Relative electrolyte leakage (Figure 3H) showed rapid growth in Tianyou2238. This result showed that ROS induced lipid peroxidation and the level of injury depended on the cold-resistant properties of the cultivars. Our findings are in agreement with previous study that cold-tolerant species, such as Santalum album (Zhang et al., 2017), Vitis amurensis (Xu et al., 2014), Solanum lycopersicum (Chen et al., 2015), B. rape (Ma et al., 2019), and B. napus (Pu et al., 2019a) have strong protective enzyme activity and high content of soluble regulators which can reduce ROS production. The present physiochemical study confirmed that cultivar 16NTS309 had significantly higher cold resistance than cultivar Tianyou 2238.

\section{The Variation of Cell Ultrastructure Alterations Caused by Cold Stress}

The present studies showed that cold stress of winter B. napus is associated with pronounced modifications in the ultrastructure of leaf cells. Wise et al. (1983) reported that ultrastructural changes of cold-sensitive species are thought to be more pronounced and induced more quickly in plants. In the present study, more obvious ultrastructural alterations in leaf mesophyll including the damage of membrane system, destruction of chloroplast and swelling of mitochondria were observed in cold-sensitive variety of Tianyou 2238 compared to cold-resistant cultivar 16NTS309. Similar damage in the leaf mesophyll cell ultrastructures was investigated in B. napus against cold stress (Stefanowska et al., 2002; Pu et al., 2019a). Previous research reported that chloroplasts are thought to be the first and most severely affected organelle (Kratsch and Wise, 2000), and cold stress may lead to unstacking of grana and disintegration of the chloroplast envelope (Klein, 1960; Kislyuk, 1963; Jagels, 1970; Taylor and Craig, 1971; Murphy and Wilson, 1981; Kratsch and Wise, 2000; Vella et al., 2012). In our study, cold stress affected more obviously in chloroplast shape and caused more significant ultra-structure changes in weak cold resistant variety Tianyou2238 than cold-resistant cultivar 16NTS309. The changes of chloroplast shape also occurred in chilling-sensitive plants such as mung bean (Ishikawa, 1996) and Arabidopsis (Ristic and Ashworth, 1993). Mitochondrial shape and internal composition changes including mitochondrial swelling and loss of cristae within mitochondria also occurred in $B$. napus responding to plant chilling in cold-sensitive plants (Ilker et al., 1976; Murphy and Wilson, 1981; Ishikawa, 1996; Lee et al., 2002) (Stefanowska et al., 2002; Pu et al., 2019a). The alterations of mitochondrial ultrastructure were observed more in Tianyou2238 while less in cold-resistant variety of 16NTS309 after cold stress, which were consistent with those reported previously.

\section{Sources of $\mathrm{O}_{2}^{-}$}

ROS signals are known to form signatures during the biotic and abiotic stress responses of plants. For example, there is a quick release of ROS, called an oxidative burst, following stress, which is an important signature not only for the local immune response but also for cell-to-cell communication (Miller et al., 2009; Miller 


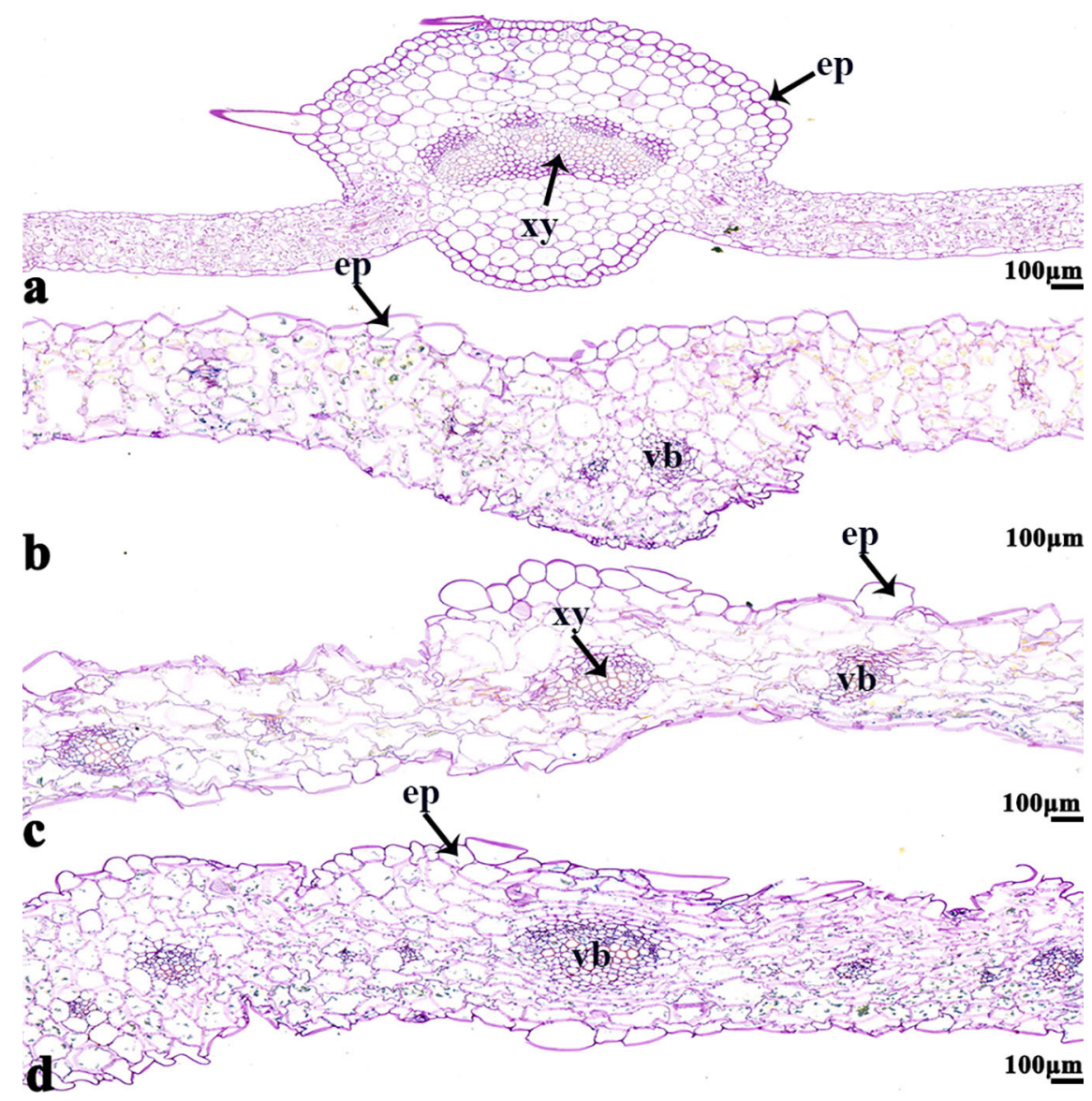

FIGURE 8 | B. napus cultivars 16NTS309 and Tianyou2238 under non-cold (A, C) and cold stress (B, D) conditions for $48 \mathrm{~h}$. The deepest leaf vein samples with blue formazan precipitate areas in 16NTS309 (A, B) and Tianyou2238 (C, D) were sectioned for morphoanatomical analysis. ep, epidermis; xy, xylem; vb, vascular bundle. Scale bars $=100 \mu \mathrm{m}$.

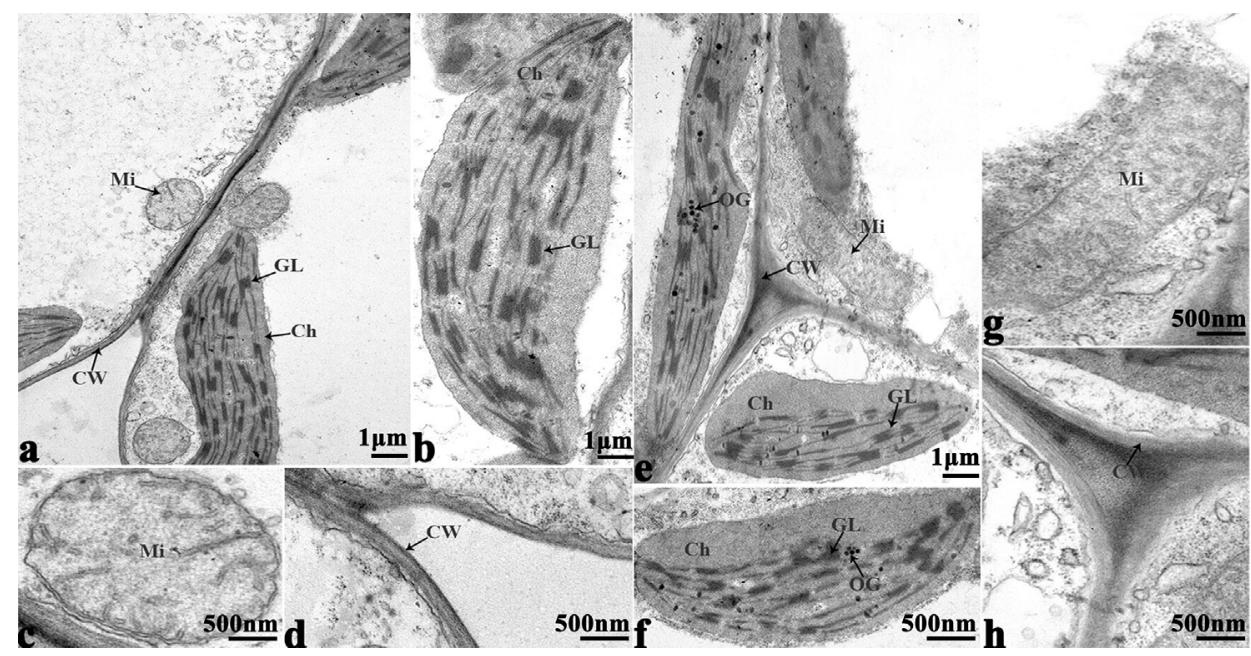

FIGURE 9 | Transmission electron micrographs of leaf ultrastructure from cultivar 16NTS309 under non-cold (A-D) and cold stress (E-H) conditions for 48 h. Mi, mitochondria; Ch, chloroplast; GL, granum lamellae; OG, osmiophilic globule; CW, cytoderm.Scale bars $=1 \mu \mathrm{m}$ and $500 \mathrm{~nm}$. 


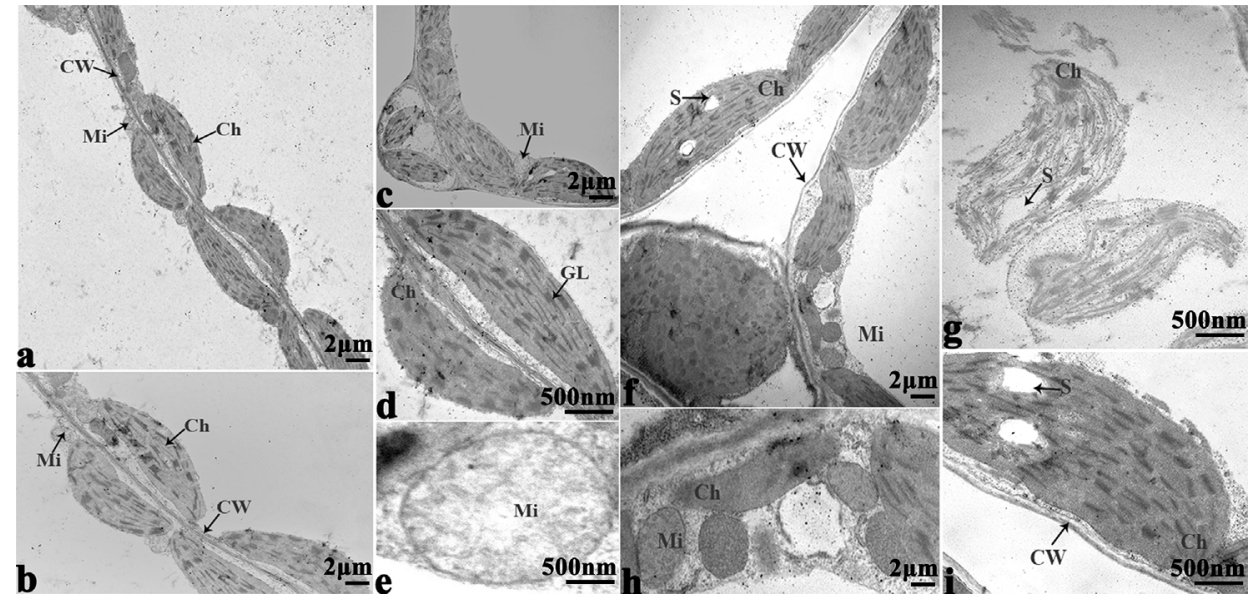

FIGURE 10 | Transmission electron micrographs of leaf ultrastructure from cultivar Tianyou2238 under non-cold (A-E) and cold stress (F-I) conditions for 48 h. Mi, mitochondria; Ch, chloroplast; GL, granum lamellae; S, starch granules; OG, osmiophilic globule; CW, cytoderm. Scale bars = 2 m and 500 nm.
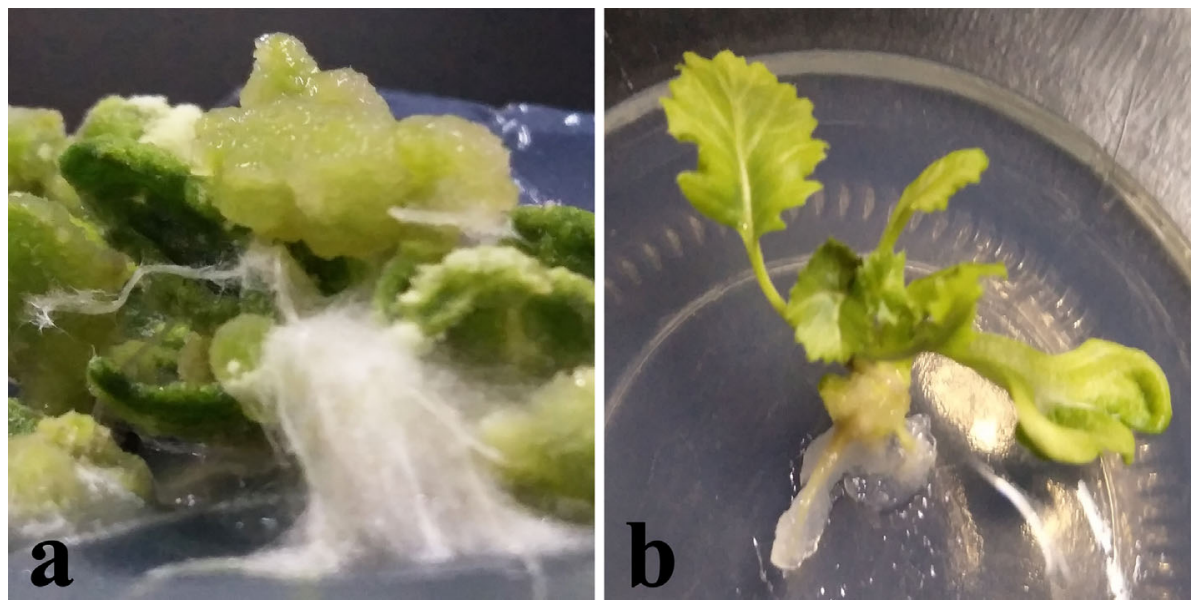

FIGURE 11 | Plant callus system for leaf segments of B. napus cultivar Tianyou2238 (cold sensitive). To characterize callus growth in response to cold stress, calluses were grown in 200-ml flasks containing $50 \mathrm{ml}$ of liquid MS medium. After four weeks incubation, the formed calluses (a) and plants (b) were divided into groups: one was maintained at $25^{\circ} \mathrm{C}$ as the non-cold control and the other was subjected to cold stress at $4^{\circ} \mathrm{C}$.

et al., 2010). In both cultivars, the $\mathrm{O}_{2}{ }^{-}$signals were distributed mainly in cambium tissue, meristematic cells, mesophyll cytoplasm, and surrounding the cell walls of root (Figures $5 \mathrm{C}$, D, G, H), stem (Figures 6C, D, G, H), leaves (Figures 7B, D), and leaf vein (Figures $\mathbf{8 B}, \mathbf{D}$ ), but the quantities varied. This phenomenon can be explained visually as follows (Figure 13). $\mathrm{O}_{2}{ }^{-}$are produced in the cell wall and are correlated with cell wall peroxidases (Bindschedler et al., 2006) and plasma membrane NADPH oxidases (Torres et al., 2002; Suzuki et al., 2011). These enzymes can translocate electrons across the plasma membrane and reduce extracellular oxygen to yield $\mathrm{O}_{2}{ }^{-}$in the cell wall. The intracellular production of a lot of $\mathrm{O}_{2}{ }^{-}$(Zurbriggen et al., 2010; Singh et al., 2019; Qi et al., 2020) may be because organelles with high oxidizing metabolic activity or with an intense rate of electron flow, such as chloroplasts and mitochondria (Mittler et al., 2004; Yao and Greenberg, 2006), work to produce $\mathrm{O}_{2}{ }^{-}$in the mesophyll cytoplasm (Liu et al., 2007; Zurbriggen et al., 2009; Zurbriggen et al., 2010) of plant cells. Our studies found that the meristem of the root, which has mitochondria but no chloroplasts, produced more $\mathrm{O}_{2}{ }^{-}$than the other tissues. The mitochondria respiratory chain continuously produces $\mathrm{O}_{2}{ }^{-}$ because of the numerous electron transfer reactions that take place in the presence of oxygen (Figures 12D-F). These results make it clear that mitochondria produce $\mathrm{O}_{2}{ }^{-}$. A greater $\mathrm{O}_{2}{ }^{-}$ content accumulated in palisade tissue and mesophyll cells compared with that in other leaf cells. This result indicated 


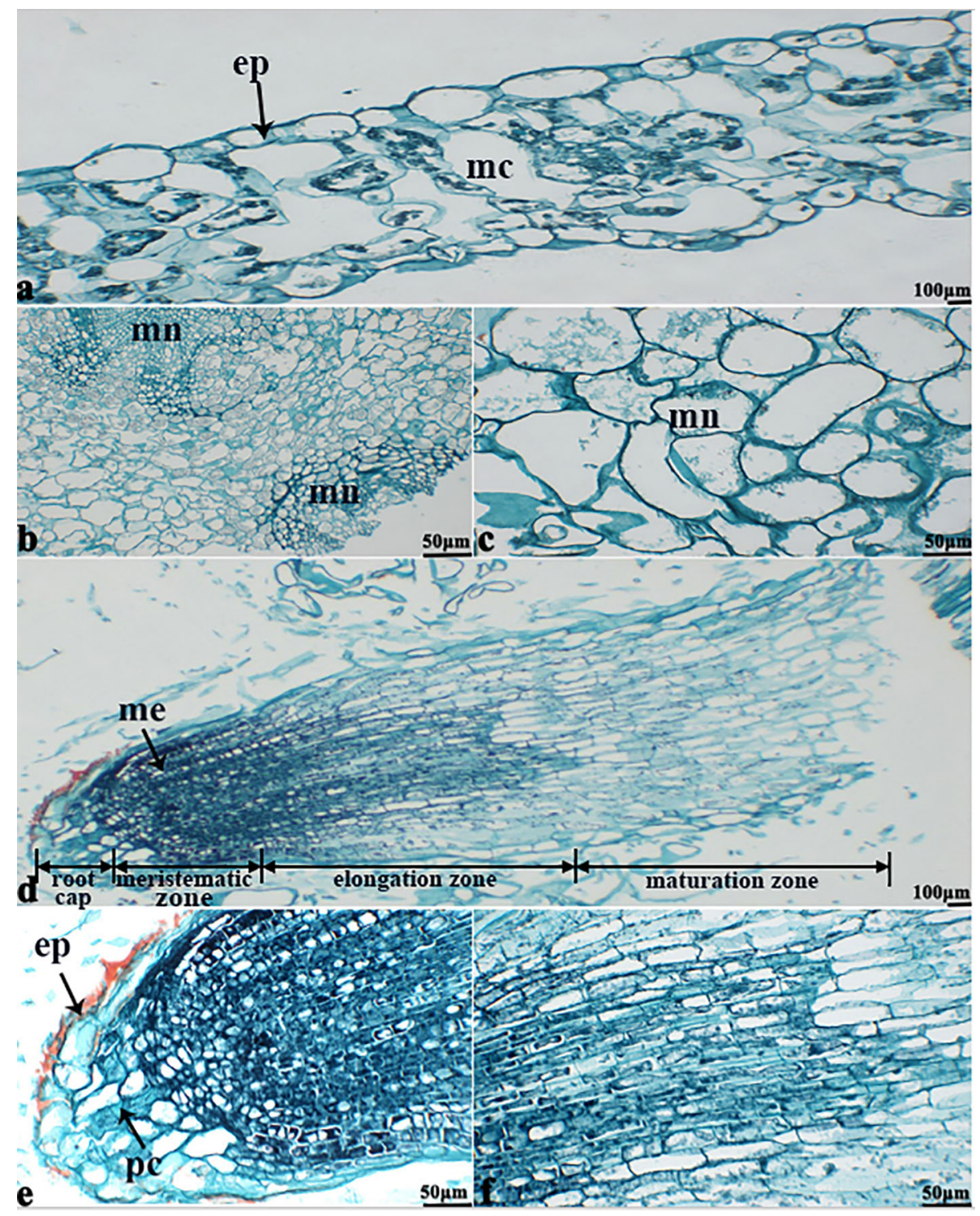

FIGURE 12 | The deepest leaf (A), callus (B, C), root (D-F) samples with blue formazan precipitate areas from the callus of cultivar Tianyou2238 were sectioned for morphoanatomical analyses. ep, epidermis; mc, mesophyll cell; mn, meristematic nodule; me, meristem; pc, parenchymal cell. Scale bars = 50 mm and $100 \mu m$.

that chloroplasts play an active role in the production of $\mathrm{O}_{2}^{-}$. These findings confirm previous reports that chloroplasts and mitochondria play important roles in $\mathrm{O}_{2}^{-}$production.

\section{$\mathrm{O}_{2}^{-}$Was a Highly Dynamic Signalling Molecules}

ROS exists in different forms with significantly different molecular properties (Schmidt and Schippers, 2015). For example, short-lived $\mathrm{O}_{2}{ }^{-}$are unable to passively through the membrane's lipid bilayer (Mittler et al., 2011). In addition, $\mathrm{O}_{2}{ }^{-}$ could be easily converted into hydrogen peroxide $\left(\mathrm{H}_{2} \mathrm{O}_{2}\right)$ by variety of reactions (Gilroy et al., 2016; Toyota et al., 2018; Singh et al., 2019) that readily transfers across membranes passively. Previous study reported that $\mathrm{O}_{2}{ }^{-}$depending on the cellular environment can travel 50-500 nm (Saran and Bors, 1989; Pitzschke et al., 2006; Schmidt and Schippers, 2015). Our studies also found that the root structure of cambium, which appeared $\mathrm{O}_{2}^{-}$bursts, $\mathrm{O}_{2}^{-}$signals can spread throughout cells in different directions (Figure 5H). We established a sterile rapid propagation system for leaf segments of Tianyou2238 and proved $\mathrm{O}_{2}{ }^{-}$bursts were appeared in the cells of meristematic zone and $\mathrm{O}_{2}{ }^{-}$gradually increased in the cells of elongation zone (Figure 12D). Thus, those results strengthen the view of $\mathrm{O}_{2}{ }^{-}$as highly dynamic signaling molecules. They also found the existence of the auto-propagating characteristics of the ROS wave and ROS can long distance auto-propagating signals (Takeda et al., 2008; Mittler et al., 2011; Singh et al., 2019). Based on this study speculated that not only ROS wave presented in $B$. 


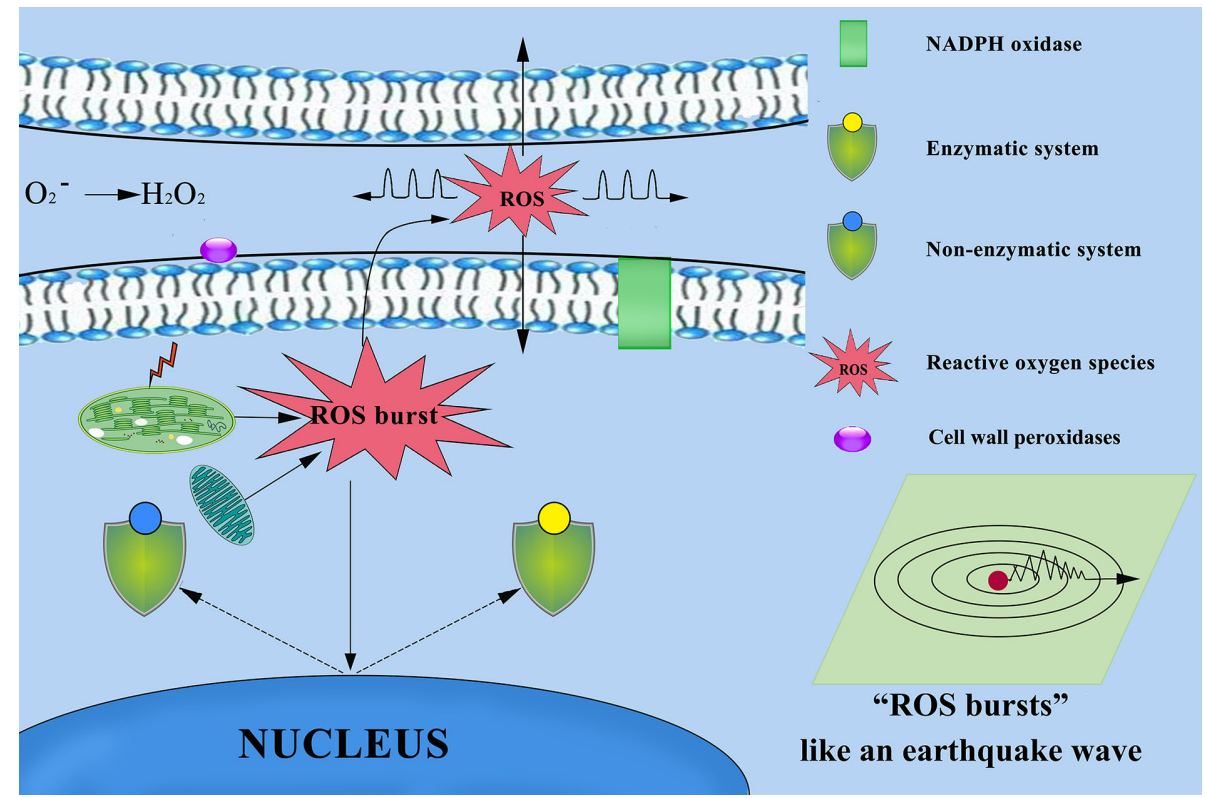

FIGURE 13 | Mechanism of reactive oxygen species (ROS) diffusion in cytoplasmic and other cells. Chloroplasts, mitochondria, cell wall peroxidases, and plasma membrane NADPH oxidases play important roles in ROS production. ROS as highly dynamic signalling molecules that ROS propagate throughout the different tissues and cells, and between different organelles and cells over long distances. When the plant defence system collapses, excessive accumulation of ROS from multiple sources results in ROS bursts that damage other surrounding cells and severely damage cellular structures.

napus, but also ROS signaling as a dynamic process that occurs within cells between different organelles, as well as between cells over long distances (Figure 13). ROS signals are known to form signatures during the biotic and abiotic stress responses of plants. During normal metabolic processes, plant cells produce a variety of ROS, including the $\mathrm{O}_{2}^{-}, \mathrm{H}_{2} \mathrm{O}_{2}$ and hydroxyl radicals (O'brien et al., 2012) and there is a quick release of ROS, following cold stress, which is an important signature not only for the local immune response but also for cell-to-cell communication (Miller et al., 2009; Miller et al., 2010; Ma et al., 2019; Qi et al.,2020).

\section{CONCLUSION}

In our study, physiological, biochemical, and cytological methods were used to investigate the plant's response to cold stress in two B. napus cultivars 16 NTS309 and Tianyou2238. The results showed that cold-tolerant B. napus of 16 NTS309 has strong protective enzyme activity and high content of soluble regulators, which can increase the cold resistance and reduce the production of ROS. More obvious ultrastructural alterations in leaf mesophyll were observed in Tianyou2238 compared to 16NTS309. From the above discussion and findings, it is concluded that 16NTS309 cultivar is cold-tolerant and Tianyou2238 cultivar is cold-sensitive. We also found that in both cultivars $\mathrm{O}_{2}{ }^{-}$signals were distributed mainly in cambium tissue, meristematic cells, mesophyll cytoplasm, and surrounding the cell walls of root, stem, leaves, and leaf vein by morphoanatomical analysis, while the quantities varied. These results strengthened the view of $\mathrm{O}_{2}{ }^{-}$as highly dynamic signaling molecules. This study shed light on the physiological, biochemical cytology changes associated with the response to cold stress of $B$. napus which would be helpful in cold-resistant varieties breeding. Further studies will be necessary to clarify the regulating mechanisms of 16NTS309 in cold response.

\section{DATA AVAILABILITY STATEMENT}

All datasets generated for this study are included in the article/ supplementary material.

\section{AUTHOR CONTRIBUTIONS}

WQ and WS conceived and designed the study. WQ, WF, LM, SL, and PW conducted the experiments. WQ, WS, ZQ, SL, CC, and CY analyzed the data. JW, ZQ, and YW contributed reagents, materials, and analysis tools. WQ wrote the manuscript. We thank Margaret Biswas, $\mathrm{PhD}$, from Liwen Bianji, Edanz Group China (www.liwenbianji.cn/ac), for editing the English text of a draft of this manuscript. "Sections of this manuscript are released as a pre-print at [Reactive oxygen species as important regulators of cell division. bioRxiv. doi: https://doi.org/10.1101/2020. 03. 06. 980474], (Qi, W., Ma, L., Wang, F., Wang, P., Wu, J., Wang, J., et al.)”. 


\section{ACKNOWLEDGMENTS}

This study was financially supported by the Research Program Sponsored by Gansu Provincial Key Laboratory of Aridland Crop Science, Gansu Agricultural University (No.GSCS-2020-Z1); Agriculture Research System of China (CARS-12); the

\section{REFERENCES}

Ali, S., Gill, R., Mwamba, T., Zhang, N., Lv, M., Ulhassan, Z., et al. (2018a). Differential cobalt-induced effects on plant growth, ultrastructural modifications, and antioxidative response among four Brassica napus (L.) cultivars. Int. J. Environ. Sci. Technol. (Tehran) 15, 2685-2700. doi: 10.1007/ s13762-017-1629-z

Ali, S., Jin, R., Gill, R. A., Mwamba, T. M., Zhang, N., Islam, F., et al. (2018b). Beryllium stress-induced modifications in antioxidant machinery and plant ultrastructure in the seedlings of black and yellow seeded oilseed rape. Bio Med. Res. Int. 2018, 1-14. doi: 10.1155/2018/1615968

Apel, K., and Hirt, H. (2004). Reactive oxygen species: metabolism, oxidative stress, and signal transduction. Annu. Rev. Plant Biol. 55, 373-399. doi: 10.1146/annurev.arplant.55.031903.141701

Asada, K., and Takahashl, M. (1987). "Production and scavenging of active oxygen in photosynthesis," in Photoinhibition. Eds. D. J. Kyle, C. B. Osmond and C. J. Arntzen (Amsterdam, FL: Elsevier Science Publishers), 227-287.

Bajji, M., Kinet, J.-M., and Lutts, S. (2002). The use of the electrolyte leakage method for assessing cell membrane stability as a water stress tolerance test in durum wheat. Plant Growth Regul. 36, 61-70. doi: 10.1023/A:1014732714549

Banerjee, A., Tripathi, D. K., and Roychoudhury, A. (2018). Hydrogen sulphide trapeze: environmental stress amelioration and phytohormone crosstalk. Plant Physiol. Biochem. 132, 46-53. doi: 10.1016/j.plaphy.2018.08.028

Barna, B., Fodor, J., Harrach, B., Pogány, M., and Király, Z. (2012). The Janus face of reactive oxygen species in resistance and susceptibility of plants to necrotrophic and biotrophic pathogens. Plant Physiol. Biochem. 59, 37-43. doi: 10.1016/j.plaphy.2012.01.014

Bates, L. S., Waldren, R. P., and Teare, I. (1973). Rapid determination of free proline for water-stress studies. Plant Soil 39, 205-207. doi: 10.1007/ BF00018060

Bindschedler, L. V., Dewdney, J., Blee, K. A., Stone, J. M., Asai, T., Plotnikov, J., et al. (2006). Peroxidase dependent apoplastic oxidative burst in Arabidopsis required for pathogen resistance. PlJ 47, 851-863. doi: 10.1111/j.1365313X.2006.02837.x

Bowers, M. C. (1994). "Environmental effects of cold on plants," in PlantEnvironment Interactions. Ed. R. E. Wilkinson (New York, FL: Marcel Dekker), 391-411.

Buysse, J., and Merckx, R. (1993). An improved colorimetric method to quantify sugar content of plant tissue. J. Exp. Bot. 44, 1627-1629. doi: 10.1093/jxb/ 44.10.1627

Campos, P. S., Nia Quartin, V., Chicho Ramalho, J., and Nunes, M. A. (2003). Electrolyte leakage and lipid degradation account for cold sensitivity in leaves of Coffe a sp. plants. J. Plant Physiol. 160, 283-292. doi: 10.1078/0176-161700833

Chen, S., and Dickman, M. B. (2004). Bcl-2 family members localize to tobacco chloroplasts and inhibit programmed cell death induced by chloroplasttargeted herbicides. J. Exp. Bot. 55, 2617-2623. doi: 10.1093/jxb/erh275

Chen, H., Chen, X., Chen, D., Li, J., Zhang, Y., and Wang, A. (2015). A comparison of the low temperature transcriptomes of two tomato genotypes that differ in freezing tolerance: Solanum lycopersicum and Solanum habrochaites. BMC Plant Biol. 15, 132. doi: 10.1186/s12870-015-0521-6

Dhindsa, R. S., Plumb-Dhindsa, P., and Thorpe, T. A. (1981). Leaf senescence: correlated with increased levels of membrane permeability and lipid peroxidation, and decreased levels of superoxide dismutase and catalase. J. Exp. Bot. 32, 93-101. doi: 10.1093/jxb/32.1.93

Dietz, K. J., Jacob, S., Oelze, M. L., Laxa, M., Tognetti, V., De Miranda, S. M., et al. (2006). The function of peroxiredoxins in plant organelle redox metabolism. J. Exp. Bot. 57, 1697-1709. doi: 10.1093/jxb/erj160
Agriculture Research System of Gansu Province (GARS-TSZ-1); the Youth Program of Chengdu Normal University (CS19ZC03); Undergraduate innovation and entrepreneurship projects (201814389095; 201814389001; 201814389066; 201814389015); and the education department of Sichuan Province innovation team projects (15TD0036).

Elstner, E. F., and Heupel, A. (1976). Inhibition of nitrite formation from hydroxylammoniumch-loride: a simple assay for superoxide dismutase. Anal. Biochem. 70, 616-620. doi: 10.1016/0003-2697(76)90488-7

Gajewska, E., and Skłodowska, M. (2007). Effect of nickel on ROS content and antioxidative enzyme activities in wheat leaves. BioMetals 20, 27-36. doi: 10.1007/s10534-006-9011-5

Gill, S. S., and Tuteja, N. (2010). Reactive oxygen species and antioxidant machinery in abiotic stress tolerance in crop plants. Plant Physiol. Biochem. 48, 909-930. doi: 10.1016/j.plaphy.2010.08.016

Gilroy, S., Białasek, M., Suzuki, N., Górecka, M., Devireddy, A. R., Karpiński, S., et al. (2016). ROS, calcium, and electric signals: key mediators of rapid systemic signaling in plants. Plant Physiol. 171, 1606-1615. doi: 10.1104/ pp.16.00434

Gokul, A., Roode, E., Klein, A., and Keyster, M. (2016). Exogenous 3, 3'diindolylmethane increases Brassica napus L. seedling shoot growth through modulation of superoxide and hydrogen peroxide content. J. Plant Physiol. 196, 93-98. doi: 10.1016/j.jplph.2016.03.013

Huang, Z., Zhao, N., Qin, M., and Xu, A. (2018). Mapping of quantitative trait loci related to cold resistance in Brassica napus L. J. Plant Physiol. 231, 147-154. doi: 10.1016/j.jplph.2018.09.012

Huang, H., Ullah, F., Zhou, D.-X., Yi, M., and Zhao, Y. (2019). Mechanisms of ROS regulation of plant development and stress responses. Front. Plant Sci. 10, 800-810. doi: 10.3389/fpls.2019.00800

Ilker, R., Waring, A. J., Lyons, J., and Breidenbach, R. (1976). The cytological responses of tomato-seedling cotyledons to chilling and the influence of membrane modifications upon these responses. Protoplasma 90, 229-252. doi: $10.1007 / \mathrm{BF} 01275677$

Ishikawa, H. A. (1996). Ultrastructural features of chilling injury: injured cells and the early events during chilling of suspension-cultured mung bean cells. Am. J. Bot. 83, 825-835. doi: 10.1002/j.1537-2197.1996.tb12774.x

Jagels, R. (1970). Photosynthetic apparatus in Selaginella. II. Changes in plastid ultrastructure and pigment content under different light and temperature regimes. Can. J. Bot. 48, 1853-1860. doi: 10.1139/b70-271

John, R., Pandey, R., Sopory, S., and Rajam, M. (2010). Engineering antioxidant enzymes for abiotic stress tolerance in plants. J. Plant Biol. 37, 1-18. doi: 10.1007/978-81-322-2283-5-29

Kang, H. M., and Saltveit, M. E. (2001). Activity of enzymatic antioxidant defense systems in chilled and heat shocked cucumber seedling radicles. Physiol. Plant 113, 548-556. doi: 10.1034/j.1399-3054.2001.1130414.x

Kishor, P. K., Sangam, S., Amrutha, R., Laxmi, P. S., Naidu, K., Rao, K. S., et al. (2005). Regulation of proline biosynthesis, degradation, uptake and transport in higher plants: its implications in plant growth and abiotic stress tolerance. Curr. Sci. 88 (3), 424-438.

Kislyuk, I. M. (1963). Morphological and functional changes of chloroplasts after cooling of leaves of Cuminis sativus L. Ed. A. S. Troshin (London, FL: Pergamon Press), 59-63.

Klein, S. (1960). The effect of low temperature on the development of the lamellar system in chloroplasts. J. Cell Biol. 8, 529-538. doi: 10.1083/jcb.8.2.529

Kratsch, H., and Wise, R. R. (2000). The ultrastructure of chilling stress. Plant Cell Environ. 23, 337-350. doi: 10.1046/j.1365-3040.2000.00560.x

Kumar, D., Yusuf, M. A., Singh, P., Sardar, M., Sarin, N. B., and Biosciences, J. (2014). Histochemical detection of superoxide and $\mathrm{H}_{2} \mathrm{O}_{2}$ accumulation in Brassica juncea seedlings. Bio Protoc. 4, e1108. doi: 10.21769/BioProtoc.1108

Lagercrantz, U., and Lydiate, D. J. (1996). Comparative genome mapping in Brassica. Genetics 144, 1903-1910.

Lalk, I., and Dörffling, K. (1985). Hardening, abscisic acid, proline and freezing resistance in two winter wheat varieties. Physiol. Plant 63, 287-292. doi: 10.1111/j.1399-3054.1985.tb04267.x 
Lee, B.-H., Lee, H., Xiong, L., and Zhu, J.-K. (2002). A mitochondrial complex I defect impairs cold-regulated nuclear gene expression. Plant Cell 14, 12351251. doi: 10.1111/j.1365-3040.1983.tb01165.x

Li, L., Staden, J. V., and Jäger, A. (1998). Effects of plant growth regulators on the antioxidant system in seedlings of two maize cultivars subjected to water stress. Plant Growth Regul. 25, 81-87. doi: 10.1023/A:1010774725695

Liu, Y., Ren, D., Pike, S., Pallardy, S., Gassmann, W., and Zhang, S. (2007). Chloroplast-generated reactive oxygen species are involved in hypersensitive response-like cell death mediated by a mitogen-activated protein kinase cascade. PlJ 51, 941-954. doi: 10.1111/j.1365-313X.2007.03191.x

Liu, Z., Sun, W., Yang, N., Wang, Y., He, L., Zhao, C., et al. (2013). Morphology and physiological characteristics of cultivars with different levels of cold-resistance in winter rapeseed (Brassica campestris L.) during cold acclimation. Sci. Agric. Sin. 46, 4679-4687. doi: 10.3864/j.issn.0578-1752.2013.22.005

Lushchak, V. I. (2014). Free radicals, reactive oxygen species, oxidative stress and its classification. Chem.-Biol. Interact. 224, 164-175. doi: 10.1016/j.cbi.2014.10.016

Lyons, J. M. (1973). Chilling injury in plants. Annu. Rev. Plant Physiol. 24, 445466. doi: 10.1146/annurev.pp.24.060173.002305

Ma, Y., Zhang, Y., Lu, J., and Shao, H. (2009). Roles of plant soluble sugars and their responses to plant cold stress. Afr. J. Biotechnol. 8, 2004-2010.

Ma, L., Coulter, J. A., Liu, L., Zhao, Y., Chang, Y., Pu, Y., et al. (2019). Transcriptome Analysis Reveals Key Cold-Stress-Responsive Genes in Winter Rapeseed (Brassica rapa L.). Int. J. Mol. Sci. 20:1071. doi: 10.3390/ijms20051071

Marcec, M. J., Gilroy, S., Poovaiah, B., and Tanaka, K. (2019). Mutual interplay of $\mathrm{Ca}^{2+}$ and ROS signaling in plant immune response. Plant Sci. 283, 343-354. doi: $10.1016 /$ j.plantsci.2019.03.004

Meyer, Y., Belin, C., Delorme-Hinoux, V., Reichheld, J. P., and Riondet, C. (2012). Thioredoxin and glutaredoxin systems in plants: molecular mechanisms, crosstalks, and functional significance. Antioxid. Redox Signal. 17, 11241160. doi: 10.1089/ars.2011.4327

Miller, G., Schlauch, K., Tam, R., Cortes, D., Torres, M. A., Shulaev, V., et al. (2009). The plant NADPH oxidase RBOHD mediates rapid systemic signaling in response to diverse stimuli. Sci. Signaling 2, ra45-ra45. doi: 10.1126/scisignal.2000448

Miller, G., Suzuki, N., Ciftci-Yilmaz, S., and Mittler, R. (2010). Reactive oxygen species homeostasis and signaling during drought and salinity stresses. Plant Cell Environ. 33, 453-467. doi: 10.1111/j.1365-3040.2009.02041.x

Min, K., Son, H., Lee, J., Choi, G. J., Kim, J.-C., and Lee, Y.-W. (2012). Peroxisome function is required for virulence and survival of Fusarium graminearum. Mol. Plant-Microbe Interact. 25, 1617-1627. doi: 10.1094/MPMI-06-12-0149-R

Mittler, R., Vanderauwera, S., Gollery, M., and Van Breusegem, F. (2004). Reactive oxygen gene network of plants. Trends Plant Sci. 9, 490-498. doi: 10.1016/ j.tplants.2004.08.009

Mittler, R., Vanderauwera, S., Suzuki, N., Miller, G., Tognetti, V. B., Vandepoele, K., et al. (2011). ROS signaling: the new wave? Trends Plant Sci. 16, 300-309. doi: 10.1016/j.tplants.2011.03.007

Møller, I. M., and Sweetlove, L. J. (2010). ROS signalling-specificity is required. Trends Plant Sci. 15, 370-374. doi: 10.1016/j.tplants.2010.04.008

Murphy, C., and Wilson, J. (1981). Ultrastructural features of chilling-injury in Episcia reptans. Plant Cell Environ. 4, 261-265. doi: 10.1111/1365-3040.ep11611230

Nanda, A. K., Andrio, E., Marino, D., Pauly, N., and Dunand, C. (2010). Reactive oxygen species during plant-microorganism early interactions. J. Integr. Plant Biol. 52, 195-204. doi: 10.1111/j.1744-7909.2010.00933.x

Nath, M., Bhatt, D., Prasad, R., Gill, S. S., Anjum, N. A., and Tuteja, N. (2016). Reactive oxygen species generation-scavenging and signaling during plantarbuscular mycorrhizal and Piriformospora indica interaction under stress condition. Front. Plant Sci. 7:1574:1574. doi: 10.3389/fpls.2016.01574

Noctor, G., Mhamdi, A., and Foyer, C. H. (2014). The roles of reactive oxygen metabolism in drought: not so cut and dried. Plant Physiol. 164, 1636-1648. doi: 10.1104/pp.113.233478

O'brien, J. A., Daudi, A., Butt, V. S., and Bolwell, G. P. (2012). Reactive oxygen species and their role in plant defence and cell wall metabolism. Planta 236, 765-779. doi: 10.1007/s00425-012-1696-9

Örvar, B. L., Sangwan, V., Omann, F., and Dhindsa, R. S. (2000). Early steps in cold sensing by plant cells: the role of actin cytoskeleton and membrane fluidity. PlJ 23, 785-794. doi: 10.1046/j.1365-313x.2000.00845.x

Pitzschke, A., Forzani, C., and Hirt, H. (2006). Reactive oxygen species signaling in plants. Antioxidants Redox Signaling 8, 1757-1764. doi: 10.1089/ars.2006.8.175
Pu, Y. Y., Liu, L. J., Wu, J. Y., Zhao, Y. H., Bai, J., Ma, L., et al. (2019a). Transcriptome profile analysis of winter rapeseed (Brassica napus L.) in response to freezing stress, reveal potentially connected events to freezing stress. Int. J. Mol. Sci. 20:2771. doi: 10.3390/ijms20112771

Pu, Y. Y., Zhao, Y.-H., Wu, J.-Y., Liu, L.-J., Bai, J., Ma, L., et al. (2019b). Comprehensive assessment on cold tolerance of the strong winter Brassica napus L. cultivated in northern china. Sci. Agric. Sin. 52, 3291-3308. doi: 10.3864/j.issn.0578-1752.2019.19.002 (in Chinese)

Qi, W., Tang, Y., Zhu, W., Li, D., Diao, C., Xu, L., et al. (2016). Molecular cytogenetic characterization of a new wheat-rye 1BL $1 \mathrm{RS}$ translocation line expressing superior stripe rust resistance and enhanced grain yield. Planta 244, 405-416. doi: 10.1007/s00425-016-2517-3

Qi, W., Ma, L., Wang, F., Wang, P., Wu, J., Wang, J., et al. (2020). Reactive oxygen species as important regulators of cell division. bioRxiv. 1-19. doi: 10.1101/ 2020.03.06.980474

Ristic, Z., and Ashworth, E. (1993). Changes in leaf ultrastructure and carbohydrates in Arabidopsis thaliana L.(Heyn) cv. Columbia during rapid cold acclimation. Protoplasma 172, 111-123. doi: 10.1007/BF01379368

Saran, M., and Bors, W. (1989). Oxygen radicals acting as chemical messengers: a hypothesis. Free Radic. Res. Commun. 7, 213-220. doi: 10.3109/10715768909087944

Schmidt, R., and Schippers, J. H. (2015). ROS-mediated redox signaling during cell differentiation in plants. Biochim. Biophys. Acta (BBA)-General Subj. 1850, 1497-1508. doi: 10.1016/j.bbagen.2014.12.020

Sergiev, I., Alexieva, V., and Karanov, E. (1997). Effect of spermine, atrazine and combination between them on some endogenous protective systems and stress markers in plants. Compt. Rend. Acad. Bulg. Sci. 51, 121-124.

Shao, H.-B., Chu, L.-Y., Shao, H.-B., Chu, L.-Y., Shao, M.-A., and Zhao, C.-X. (2008). Advances in functional regulation mechanisms of plant aquaporins: Their diversity, gene expression, localization, structure and roles in plant soil-water relations. Mol. Membr. Biol. 25, 179-191. doi: 10.1080/09687680801914508

Singh, S., Tripathi, D. K., Singh, S., Sharma, S., Dubey, N. K., Chauhan, D. K., et al. (2017). Toxicity of aluminium on various levels of plant cells and organism: a review. Environ. Exp. Bot. 137, 177-193. doi: 10.1016/ j.envexpbot.2017.01.005

Singh, A., Kumar, A., Yadav, S., and Singh, I. K. (2019). Reactive oxygen speciesmediated signaling during abiotic stress. Plant Gene 18:100173. doi: 10.1016/ j.plgene.2019.100173

Snowdon, R., Friedrich, T., Friedt, W., and Köhler, W. (2002). Identifying the chromosomes of the A-and C-genome diploid Brassica species B. rapa (syn. campestris) and B. oleracea in their amphidiploid B. napus. Theor. Appl. Genet. 104, 533-538. doi: 10.1007/s00122-001-0787-y

Stefanowska, M., Kuraś, M., and Kacperska, A. (2002). Low temperature-induced modifications in cell ultrastructure and localization of phenolics in winter oilseed rape (Brassica napus L. var. oleifera L.) leaves. Ann. Bot. 90, 637-645. doi: $10.1093 / \mathrm{aob} / \mathrm{mcf} 241$

Sun, W., Wu, J., Zeng, J., Zhu, H.-X., Liu, Y.-L., and Zhang, Y.-H. (2007). Primary evaluation of cold tolerance among eight winter Brassica rapa. J. Hunan Agric. Univ. (Nat. Sci.) 33, 151-155.

Sun, W.-C., Wu, J.-Y., Fang, Y., Liu, Q., Yang, R.-Y., Ma, W.-G., et al. (2010). Growth and development characteristics of winter rapeseed northern-extended from the cold and arid regions in China. Acta Agron. Sin. 36, 2124-2134. doi: 10.3724/SP.J.1006.2010.02124

Sun, W. (2013). Cultivation techniques of winter oilseed rape in northern arid and cold areas (Beijing, FL: Chinese Agricultural Press).

Suzuki, N., Miller, G., Morales, J., Shulaev, V., Torres, M. A., and Mittler, R. (2011). Respiratory burst oxidases: the engines of ROS signaling. Curr. Opin. Plant Biol. 14, 691-699. doi: 10.1016/j.pbi.2011.07.014

Takeda, S., Gapper, C., Kaya, H., Bell, E., Kuchitsu, K., and Dolan, L. (2008). Local positive feedback regulation determines cell shape in root hair cells. Sci 319, 1241-1244. doi: 10.1126/science. 1152505

Taylor, A., and Craig, A. (1971). Plants under climatic stress: II. Low temperature, high light effects on chloroplast ultrastructure. Plant Physiol. 47, 719-725. doi: $10.1104 /$ pp.47.5.719

Torres, M. A., Dangl, J. L., and Jones, J. D. (2002). Arabidopsis gp91phox homologues AtrbohD and AtrbohF are required for accumulation of reactive oxygen intermediates in the plant defense response. Proc. Natl. Acad. Sci. 99, 517-522. doi: 10.1073/pnas.012452499 
Toyota, M., Spencer, D., Sawai-Toyota, S., Jiaqi, W., Zhang, T., Koo, A. J., et al. (2018). Glutamate triggers long-distance, calcium-based plant defense signaling. Sci 361, 1112-1115. doi: 10.1126/science.aat7744

Tripathi, D. K., Singh, S., Singh, S., Srivastava, P. K., Singh, V. P., Singh, S., et al. (2017). Nitric oxide alleviates silver nanoparticles (AgNps)-induced phytotoxicity in Pisum sativum seedlings. Plant Physiol. Biochem. 110, 167177. doi: 10.1016/j.plaphy.2016.06.015

Vacca, R. A., De Pinto, M. C., Valenti, D., Passarella, S., Marra, E., and De Gara, L. (2004). Production of reactive oxygen species, alteration of cytosolic ascorbate peroxidase, and impairment of mitochondrial metabolism are early events in heat shock-induced programmed cell death in tobacco Bright-Yellow 2 cells. Plant Physiol. 134, 1100-1112. doi: 10.1104/pp.103.035956

Vacca, R. A., Valenti, D., Bobba, A., Merafina, R. S., Passarella, S., and Marra, E. (2006). Cytochrome $c$ is released in a reactive oxygen species-dependent manner and is degraded via caspase-like proteases in tobacco Bright-Yellow 2 cells en route to heat shock-induced cell death. Plant Physiol. 141, 208-219. doi: 10.1104/pp.106.078683

Vella, N. G., Joss, T. V., and Roberts, T. H. (2012). Chilling-induced ultrastructural changes to mesophyll cells of Arabidopsis grown under short days are almost completely reversible by plant re-warming. Protoplasma 249, 1137-1149. doi: 10.1007/s00709-011-0363-5

Wang, L.-P., Yang, G., Sun, W.-C., Zhang, Z.-L., Wang, Y., Dong, H.-Y., et al. (2015). Cold resistance and botanical characteristics of the hybrid progeny between winter and spring turnip rapes (Brassica campestris L.). Agric. Res. Arid. Regions 4, 291-296. doi: 10.7606/j.issn.1000-7601.2015.04.44

Wani, S. H., Sofi, P. A., Gosal, S. S., and Singh, N. B. (2010). In vitro screening of rice (Oryza sativa $\mathrm{L}$ ) callus for drought tolerance. Commun. Biometry Crop Sci. $5,108-115$.

Wanner, L. A., and Junttila, O. (1999). Cold-induced freezing tolerance in Arabidopsis. Plant Physiol. 120, 391-400. doi: 10.1104/pp.120.2.391

Wise, R. R., Mcwilliam, J., and Naylor, A. W. (1983). A comparative study of lowtemperature-induced ultrastructural alterations of three species with differing chilling sensitivities. Plant Cell Environ. 6, 525-535. doi: 10.1111/j.13653040.1983 tb01165.x.

Wu, F., Zhang, G., and Dominy, P. (2003). Four barley genotypes respond differently to cadmium: lipid peroxidation and activities of antioxidant capacity. Environ. Exp. Bot. 50, 67-78. doi: 10.1016/S0098-8472(02)00113-2

Wu, J., Sun, Y., Zhao, Y., Zhang, J., Luo, L., Li, M., et al. (2015). Deficient plastidic fatty acid synthesis triggers cell death by modulating mitochondrial reactive oxygen species. Cell Res. 25, 621-633. doi: 10.1038/cr.2015.46

Xu, W., Li, R., Zhang, N., Ma, F., Jiao, Y., and Wang, Z. (2014). Transcriptome profiling of Vitis amurensis, an extremely cold-tolerant Chinese wild Vitis species, reveals candidate genes and events that potentially connected to cold stress. Plant Mol. Biol. 86, 527-541. doi: 10.1007/s11103-014-0245-2
Yan, L., Shah, T., Cheng, Y., Yan, L. U., Zhang, X., and Zou, X. (2019). Physiological and molecular responses to cold stress in rapeseed (Brassica napus L.). J. Integr. Agric. 18, 2742-2752. doi: 10.1016/S2095-3119(18)62147-1

Yao, N., and Greenberg, J. T. (2006). Arabidopsis ACCELERATED CELL DEATH2 modulates programmed cell death. Plant Cell 18, 397-411. doi: 10.1105/tpc.105.036251

Yao, N., Tada, Y., Park, P., Nakayashiki, H., Tosa, Y., and Mayama, S. (2001). Novel evidence for apoptotic cell response and differential signals in chromatin condensation and DNA cleavage in victorin-treated oats. PlJ 28, 13-26. doi: 10.1046/j.1365-313X.2001.01109.x

Zhang, X.-K., Zhang, C.-L., Liao, X., and Wang, H. (2008). Investigation on 2008' low temperature and freeze injure on winter rape along Yangtze River. Chin. J. Oil Crop Sci. 30, 122. doi: 10.3321/j.issn:1007-9084.2008.01.023

Zhang, X., Da Silva, J. A. T., Niu, M., Li, M., He, C., Zhao, J., et al. (2017). Physiological and transcriptomic analyses reveal a response mechanism to cold stress in Santalum album L. leaves. Sci. Rep. 7:42165. doi: 10.1038/srep42165

Zhao, Y., Luo, L., Xu, J., Xin, P., Guo, H., Wu, J., et al. (2018). Malate transported from chloroplast to mitochondrion triggers production of ROS and PCD in Arabidopsis thaliana. Cell Res. 28, 448-461. doi: 10.1038/s41422-018-0024-8

Zhu, Y.-F., Wu, Y.-X., Hu, Y., Jia, X.-M., Zhao, T., Cheng, L., et al. (2019). Tolerance of two apple rootstocks to short-term salt stress: focus on chlorophyll degradation, photosynthesis, hormone and leaf ultrastructures. Acta Physiol. Plant 41:87. doi: 10.1007/s11738-019-2877-y

Zou, Q. (2000). Instruction in Plant Physiological Experiment (Beijing, FL: Chinese Agricultural Press).

Zurbriggen, M. D., Carrillo, N., Tognetti, V. B., Melzer, M., Peisker, M., Hause, B., et al. (2009). Chloroplast-generated reactive oxygen species play a major role in localized cell death during the non-host interaction between tobacco and Xanthomonas campestris pv. vesicatoria. PlJ 60, 962-973. doi: 10.1111/j.1365-313X.2009.04010.x

Zurbriggen, M. D., Carrillo, N., and Hajirezaei, M.-R. (2010). ROS signaling in the hypersensitive response: when, where and what for? Plant Signaling Behav. 5 393-396. doi: 10.4161/psb.5.4.10793

Conflict of Interest: The authors declare that the research was conducted in the absence of any commercial or financial relationships that could be construed as a potential conflict of interest.

Copyright (C) 2020 Qi, Wang, Ma, Qi, Liu, Chen, Wu, Wang, Yang, Wu and Sun. This is an open-access article distributed under the terms of the Creative Commons Attribution License (CC BY). The use, distribution or reproduction in other forums is permitted, provided the original author(s) and the copyright owner(s) are credited and that the original publication in this journal is cited, in accordance with accepted academic practice. No use, distribution or reproduction is permitted which does not comply with these terms. 